Article

\title{
Development of a Prototype for Monitoring Photovoltaic Self-Consumption Systems
}

\author{
Catalina Rus-Casas ${ }^{1,2, *} \mathbb{B}$, Gabino Jiménez-Castillo ${ }^{1}{ }^{\circledR}$, Juan Domingo Aguilar-Peña ${ }^{1}(\mathbb{D}$, \\ Juan Ignacio Fernández-Carrasco ${ }^{2}$ and Francisco José Muñoz-Rodríguez ${ }^{1,2}$ (D) \\ 1 Department of Electronic and Automatic Engineering, Universidad de Jaen, 23071 Jaen, Spain; \\ gjimenez@ujaen.es (G.J.-C.); jaguilar@ujaen.es (J.D.A.-P.); fjmunoz@ujaen.es (F.J.M.-R.) \\ 2 Centre for Advanced Studies in Energy and Environment CEAEMA, Universidad de Jaen, 23071 Jaen, Spain; \\ jifernan@ujaen.es \\ * Correspondence: crus@ujaen.es; Tel.: +34-953-212-812
}

Received: 31 October 2019; Accepted: 26 December 2019; Published: 1 January 2020

\begin{abstract}
Currently, the increasing energy consumption around the world and the environmental impact resulting from the use of fossil fuel-based energy have promoted the use of renewable energy sources such as photovoltaic solar energy. The main characteristic of this type of energy is its unpredictability, as it depends on meteorological conditions. In this sense, monitoring the power generation of photovoltaic systems (PVS) in order to analyze their performance is becoming crucial. The purpose of this paper is to design a monitoring system for a residential photovoltaic self-consumption system which employs an Internet of Things (IoT) platform to estimate the photovoltaic power generation according to solar radiation and temperature. The architecture of the developed prototype will be described and the benefits of providing the use of IoT for monitoring will be highlighted, since all data collected by the data acquisition system (DAS) may be stored in the Cloud. The comparison of the results with those of other monitoring systems was very positive, with an uncertainty that complies with the IEC61724 standard.
\end{abstract}

Keywords: Internet of Things; monitoring; photovoltaic applications

\section{Introduction}

The growth in the number of industries and the increase in societal comfort needs have increased energy demand since the end of the 20th century. The current energy model, which is mainly based on the consumption of energy from fossil fuels, shows numerous environmental and economic disadvantages, resulting from the fact that these sources are limited, which contributes to the increase in pollution levels and the increase in their price [1,2].

The need to reduce the use of these fuels for power generation is encouraging the use of renewable energies [3,4]. Among these clean energies, photovoltaic solar energy occupies an outstanding position. The decrease in cost of this technology and the large amount of solar radiation available contribute to obtaining competitive production costs compared to the energy produced by fossil fuels or other renewable sources according to various studies $[5,6]$. In these studies, the unit electricity generation cost is analyzed, depending on the source used and the size of the installation.

In recent years, photovoltaic self-consumption systems in buildings provide decentralized production, whereby users of these systems-prosumers-generate and consume their own energy. Photovoltaic self-consumption systems constitute an important challenge for distributed generation to integrate renewable energy sources into the electric grid in order to create a smart grid $[7,8]$.

One of the main features of these photovoltaic systems is the difficulty that exists in forecasting the generated energy, which depends, to a great extent, on weather conditions $[9,10]$. Therefore, it is 
necessary to use monitoring systems in order to precisely estimate the photovoltaic solar energy as a function of meteorology. In the case of monitoring photovoltaic (PV) systems, it is essential to measure meteorological parameters such as irradiance and temperature, as well as electrical parameters such as generator output power PV and inverter output power [11,12].

In large-scale photovoltaic systems, the use of monitoring systems is justified, although these systems are expensive [13]. Nevertheless, installing monitoring systems in medium and small photovoltaic systems incurs additional costs, which may discourage some users from installing these systems $[14,15]$.

To solve this type of monitoring, it would be appropriate to use data acquisition systems based on low-cost platforms. The Arduino platform, version 1, has a memory capacity of $1 \mathrm{kB}$, which is not sufficient for data storage for longer periods of time (e.g., storing nine parameters every minute a $1 \mathrm{kB}$ of memory for $6 \mathrm{~min}$ ) [16]. However, this platform has been used to develop low-cost monitoring systems for photovoltaic systems in which the data storage drawback has been solved in different ways. Moreover, portable memory modules have been considered [16-18]. However, this solution is based on periodic maintenance to prevent a lack of memory. In other cases, data storage has been solved by transferring data using the short message delivery service to a personal computer [19].

Furthermore, another possible solution to the problem of data storage may be found in the use of the Internet of Things concept (IoT). IoT allows the storage, processing and visualization of large amounts of data efficiently [19]. IoT platforms allow remote monitoring and do not need a web server dedicated only to this task. This leads to savings when designing a data acquisition system [20,21].

However, using IoT platforms to monitor photovoltaic systems is still a nascent field [22]. One of the first IoT experiences in which photovoltaic systems were involved was the management and monitoring of energy flows in a dwelling in which this type of system was installed [23]. Other studies describe IoT used together with DAS to monitor a photovoltaic system to store and manipulate photovoltaic self-consumption system performance. Furthermore, monthly reports on the operation of the photovoltaic system were achieved [14]. In order to monitor to upload the data to the IoT Arduino platform, General Packet Radio Service (GPRS), communication may be used when monitoring and uploading the data to the Arduino IoT. Moreover, the data in the IoT Cloud allows the users of the system to download data for the system from any device with an internet connection [24]. Arduino and IoT can be used together to monitor the operating parameters of photovoltaic systems, not only to provide system performance, but to detect system failures [25]. In this sense, photovoltaic systems connected to IoT have allowed monitoring and control routines to be performed with a greater efficiency than traditional monitoring systems or human inspections [26].

The solutions discussed above have been developed to stand-alone or grid-connected photovoltaic systems [27-29]. Some of these facilities use IoT and low-cost acquisition cards. However, they do not follow the recommendations defined by the IEC61724-1 standard in order to monitor photovoltaic self-consumption systems [30]. This aspect is particularly important if comparisons between different systems and the potential of this technology are to be achieved.

This paper provides a solution to the supervision of small-power photovoltaic self-consumption systems installed in homes. This type of system has grown considerably in recent years, as these systems are encouraged by Public Administrations that promote sustainable development and try to reduce the consumption of energy from non-renewable sources $[3,4]$. Under this line of action, we can observe policies that promote the implementation of energy generation with renewable sources in order to promote buildings with a near-zero energy balance (NZEB, nearly-zero-energy building). The development of photovoltaic self-consumption systems provides prosumers with energy and reduces the dependency on the electric grid. The hallmark of these systems is its modularity, which makes photovoltaic technology a viable option to generate renewable energy for residential consumption. Decentralized production is achieved, as users with photovoltaic self-consumption systems can produce and consume the energy generated at the site. 
This growing inclusion of photovoltaic self-consumption systems in the electricity market must be supported by monitoring systems which check the performance analysis of this type of system in real time, providing end-users with confidence in this technology. This task will be performed by monitoring systems that must provide detailed information on the operation of the system [31-34].

In this sense, this article provides a new approach to monitoring a small power commercial photovoltaic self-consumption system based on a developed DAS prototype and the Cloud computing concept. The prototype will use an IoT platform to upload and store all the parameters to be monitored, as defined in the standard IEC 61724-1. Moreover, a performance analysis using the estimated parameters defined in the standard will be presented to provide end-users with real-time information about their photovoltaic self-consumption systems.

This paper is organized as follows. In the next section, the developed prototype, with the aim of setting up a low-cost monitoring system, is presented. Firstly, the hardware of the measurement system is given, and then the software used is described. The results obtained are presented in Section 3. Finally, the conclusions together with future actions are given in Section 4.

\section{Materials and Methods Used to Develop the Prototype for Monitoring Photovoltaic Self-Consumption Systems}

\subsection{Description of Photovoltaic Self-Consumption System}

The monitored system is a commercial photovoltaic self-consumption system which has been installed in the Higher Polytechnic School of Jaén (latitude: $37^{\circ} 47^{\prime} 00^{\prime \prime} \mathrm{N}$ and longitude $3^{\circ} 47^{\prime} 0^{\prime \prime} \mathrm{W}$ ) at the University of Jaén. It consists of an array power of $555 \mathrm{Wp}$ STC (Standard Test Conditions) (Figure 1), and an inverter model Soladin-600, with $535 \mathrm{~W}$ of nominal power. It must be noted that STC implies a normal irradiance $\left(\mathrm{G}_{\mathrm{i}}\right)$ of $1000 \mathrm{~W} / \mathrm{m}^{2}$ and a cell temperature $\left(\mathrm{T}_{\mathrm{C}}\right)$ of $25^{\circ} \mathrm{C}$. The array power consists of three commercial photovoltaic modules, Deikko DKP-185, connected in series tilted $50^{\circ}$ to the horizontal, facing south. Additional information about the main characteristics of the PV generator can be found in Table 1.

Table 1. The main characteristics of the photovoltaic generator (PVG).

\begin{tabular}{ccc}
\hline Characteristics of the PV Generator and the Inverter & \\
\hline System & Parameter & Value \\
\hline \multirow{2}{*}{ PVG } & Number parallel modules & 1 \\
& Number serial modules & 3 \\
\hline Module & Surface & $396 \mathrm{~m}^{2}$ \\
\hline & $\mathrm{P}_{\mathrm{m}, \mathrm{STC}}$ & $555 \mathrm{~W}$ \\
& $\mathrm{~V}_{\mathrm{oc}, \mathrm{STC}}$ & $90 \mathrm{~V}$ \\
& $\mathrm{I}_{\mathrm{sc}, \mathrm{STC}}$ & $832 \mathrm{~A}$ \\
& $\mathrm{~V}_{\mathrm{m}, \mathrm{STC}}$ & $72 \mathrm{~V}$ \\
& $\mathrm{I}_{\mathrm{m}, \mathrm{STC}}$ & $77 \mathrm{~A}$ \\
\hline & Nominal power DC & $535 \mathrm{~W}$ \\
& Max power DC & $600 \mathrm{~W}$ \\
& MPP (Maximum Power Point) & $40-125 \mathrm{~V}$ \\
& Max voltage DC & $155 \mathrm{~V}$ \\
& Nominal current & $8 \mathrm{~A}$ \\
& Nominal voltage (AC) & $195-253 \mathrm{~V}$ \\
& Frequency & $495-505 \mathrm{~V}$ \\
\end{tabular}



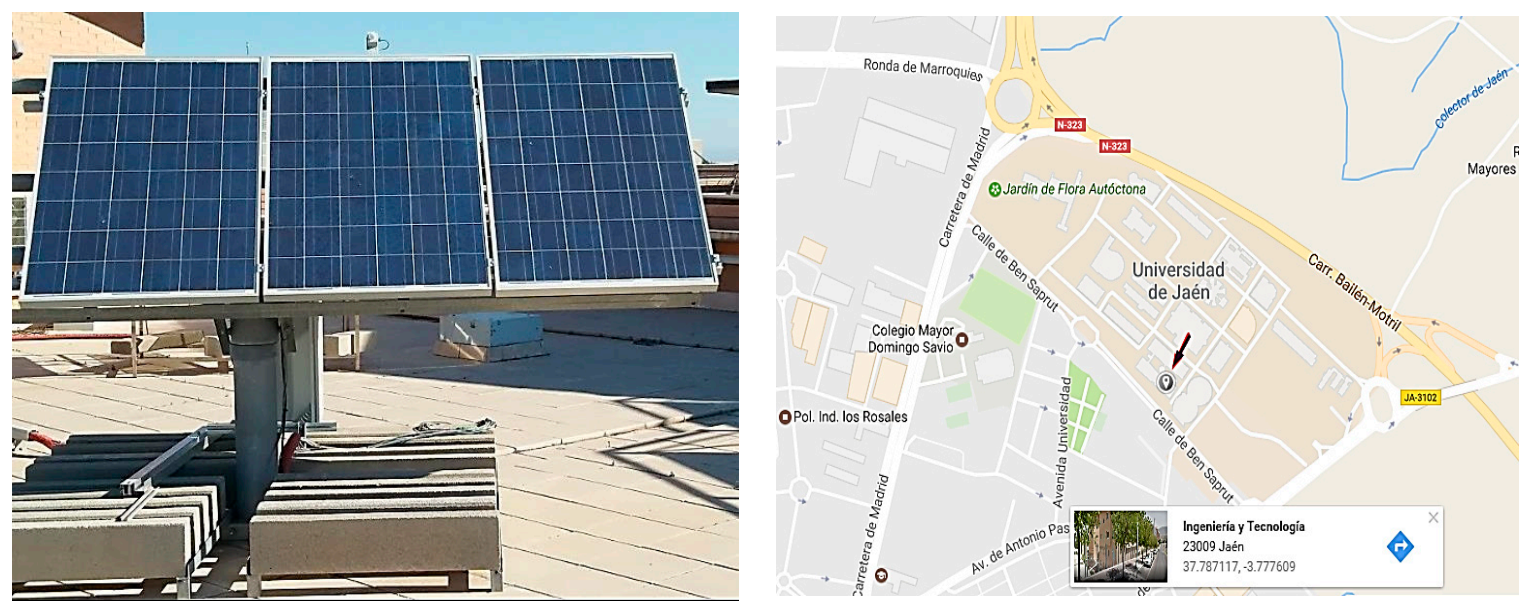

Figure 1. Photovoltaic self-consumption system at $555 \mathrm{Wp}$. Location of the photovoltaic system.

The monitored parameters concerning the array generator and the inverter, together with the metereological parameters, meet the requirements of the international standard defined IEC 61724-1 [35]. Therefore, the design of the monitoring system meets the requirements given in the class $C$ standard for small installations. According to the requirements established for this class, two meteorological parameters must be monitored: the in-plane irradiance $\left(G_{i}\right)$ and the ambient temperature $\left(T_{a m b}\right)$. Sampling and recording intervals of 1 and $60 \mathrm{~min}$, respectively, are considered. Moreover, the electrical AC parameters that are monitored at the inverter are output power $\left(\mathrm{P}_{\text {out }}\right)$ and energy $\left(\mathrm{E}_{\text {out }}\right)$. As indicated in the standard for this type of systems, electrical parameters at the generator output such as the array current $\left(\mathrm{I}_{\mathrm{A}}\right)$ and voltage $\left(\mathrm{V}_{\mathrm{A}}\right)$ are also monitored. From the latter, estimated parameters can be obtained that provide the array performance (the array output energy, $\mathrm{E}_{\mathrm{A}}$ and array yield, $\mathrm{Y}_{\mathrm{A}}$ ) the inverter performance (inverter efficiency) and the system performance (final yield, $\mathrm{Y}_{\mathrm{F}}$, and system efficiency, $\eta \mathrm{f})$.

\subsection{Architecture of the Monitoring System, Materials Used for the Development of the Prototype}

In this section, the architecture of the monitoring system is presented. Figure 2 shows the block diagram of the monitoring system that has been developed, in which the data acquisition hardware (sensors and DAS) and the communication hardware with the IoT platform are highlighted.

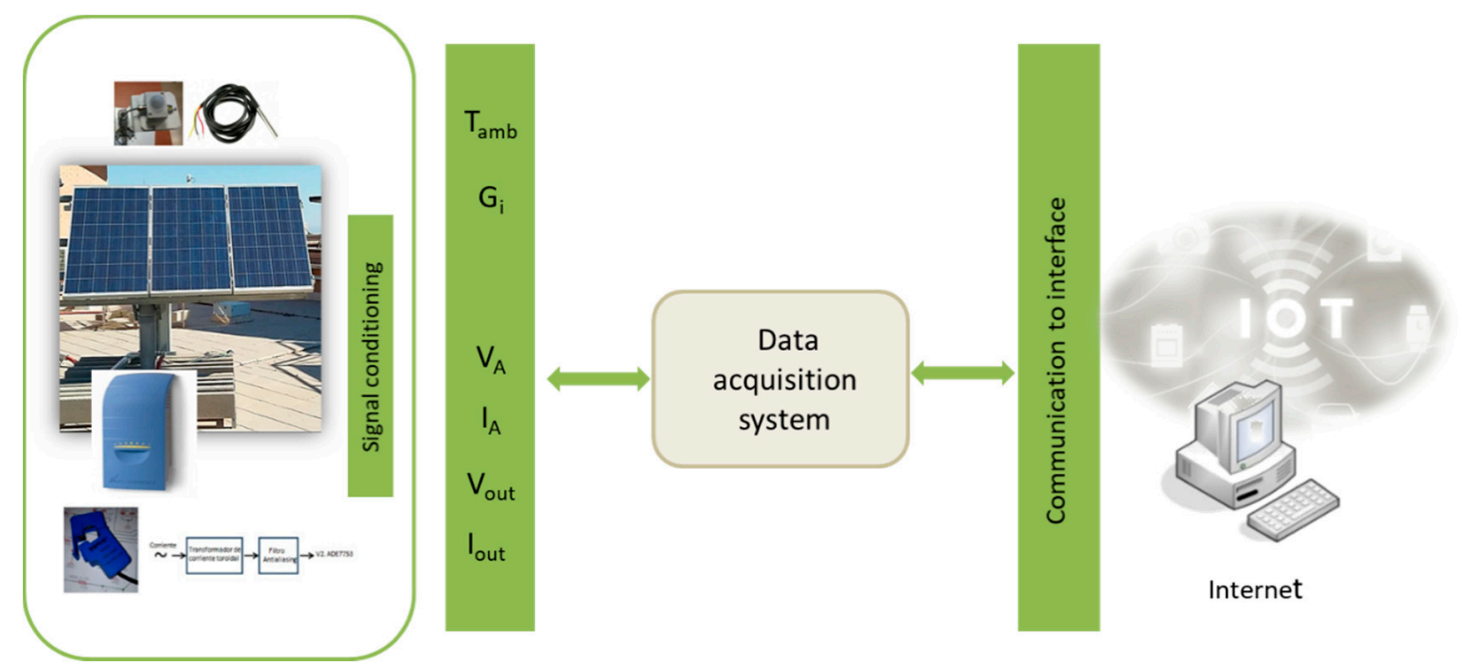

Figure 2. The block diagram of the prototype for monitoring a photovoltaic self-consumption system. 
The sensor block consists of meteorological sensors and electrical sensors. These sensors also have electronic elements for signal conditioning, which are used to adapt the level of the output signals to the DAS inputs.

Solar irradiance $\left(\mathrm{G}_{\mathrm{i}}\right)$ measurement in $\left(\mathrm{W} / \mathrm{m}^{2}\right)$ can be obtained through pyranometers or other devices designed ad hoc, such as a reference cell [27,36]. In the developed prototype, the sensor that has been used to monitor Gi is based on a matrix of silicon photodiodes which our team of researchers developed as a utility model and submitted for evaluation by the Spanish Patent and Trademark Office. After the expert evaluation process, the sensor was protected with publication number ES1214734, which is described below $[11,37]$. This sensor has been programmed so that its output provides a pulse train with a frequency which is directly proportional to the incident radiation.

To monitor the ambient temperature, the DS18B20 digital sensor [38] was used. It measures the temperature from $-55^{\circ} \mathrm{C}$ to $125^{\circ} \mathrm{C}$. One of the most versatile sensors from this group is the DS18B20 by Maxim, which provides temperature measurements with a resolution of $0.0625^{\circ} \mathrm{C}$. The DS18B20 communicates over a one-wire bus that requires only one data line and ground for communication. The DS18B20 can derive power directly from the data line, eliminating the need for an additional power supply connection. Many researchers have already taken advantage of the DS18B20 in their applications, including PV monitoring applications [36,39]. In Figure 3, the encapsulation of the $\mathrm{G}_{\mathrm{i}}$ sensor and the temperature sensor used is shown.
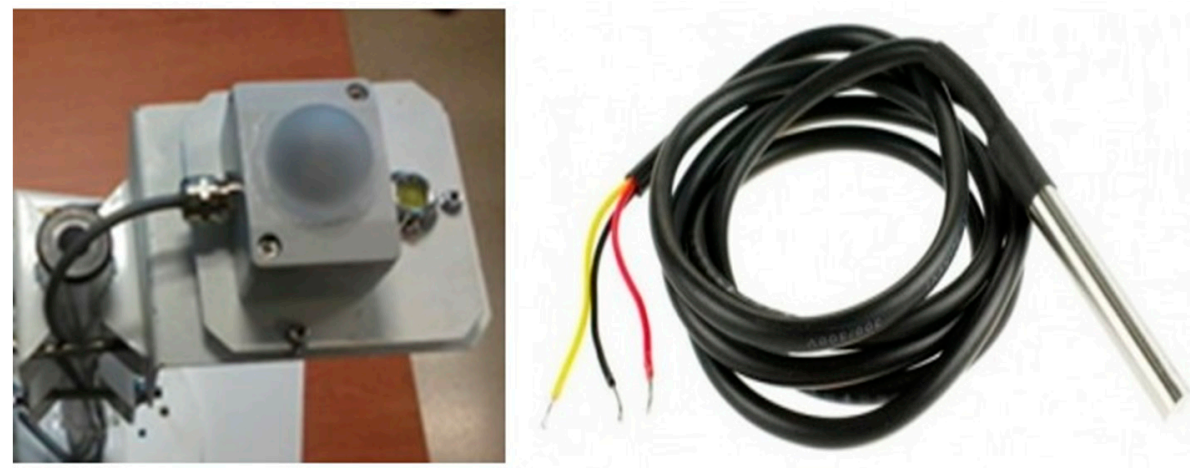

Figure 3. On the right, the sensor that measures Tamb; on the left, the sensor that measures $G_{i}$.

There are different types of sensors for current measurement $\left(\mathrm{I}_{\mathrm{A}}\right)$, such as shunt resistors, which are based on the voltage fall through a conductor $[40,41]$, and hall-effect sensors, which enable an accurate and direct current measurement. For this application, a hall-effect sensor was selected, as the shunt resistor can affect measurements when it is heated. The selected current sensor is placed on the ACS714 card as it offers different current measuring ranges, such as $\pm 5, \pm 20$, and $\pm 30 \mathrm{~A}$. In addition, the accuracy is improved with a simple $5 \mathrm{~V}$ source [42,43]. The sensor operation is based on the generation of a voltage which is directly proportional to the magnetic field produced by the current flowing through it, whose equivalence is $66 \mathrm{mV} / 1 \mathrm{~A}$.

To measure $V_{A}$ with great precision and accuracy, the IAMA3535 device was used. The IAMA3535 is a universal signal conditioning module which can isolate and convert over 100 combinations of analog signal ranges. The IAMA3535 converts and transmits signals which are linearly proportional to the input, and it allows quick setup for over 100 standard signal conversions. By utilizing the field mode of calibration, the user can customize the input and output scaling for applications. It is a signal conditioning module with galvanic isolation which is capable of converting array PV voltages between 0 and $100 \mathrm{~V}$ into voltage values located in the range of $0-5 \mathrm{~V}$, in order to send this signal to the DAS [44].

In Figure 4, the sensors used to measure the array current and voltage are shown. 


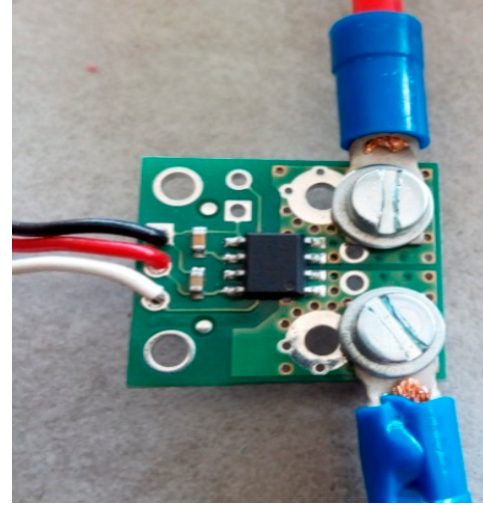

(a)

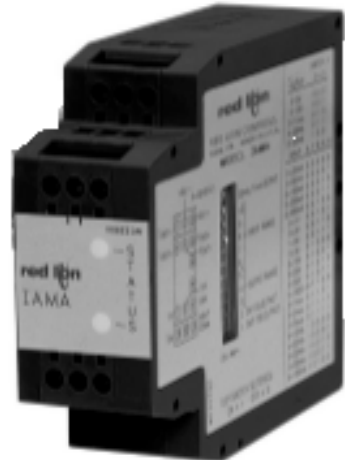

(b)

Figure 4. (a) Sensor to measure $\mathrm{I}_{\mathrm{A}}$ : sensor ACS714. (b) Sensor to measure $\mathrm{V}_{\mathrm{A}}$ : sensor IAMA3535.

To measure the AC electrical parameters at the inverter output (current, voltage, frequency, active, reactive and apparent power and energy), the integrated circuit Analog Device ADE7753 is used together with the sensor SCT-013 [45], which is connected to one of the ADE7753 inputs. In Figure 5, the sensor SCT-013 is shown, together with the block diagram showing the connection to the integrated circuit. The ADE7753 circuit is an energy monitor. It is a mixed processor (digital/analog) which provides information about the power used (active, reactive and apparent), using output pulses of variable frequency or following the standard serial protocol. It has two inputs: one is proportional to the load voltage, and the other one is proportional to the current that circulates through the load. Its operation consists of digitalizing the signals which are related to the load voltage and current and multiplying them so that the result is proportional to the load power $[46,47]$.
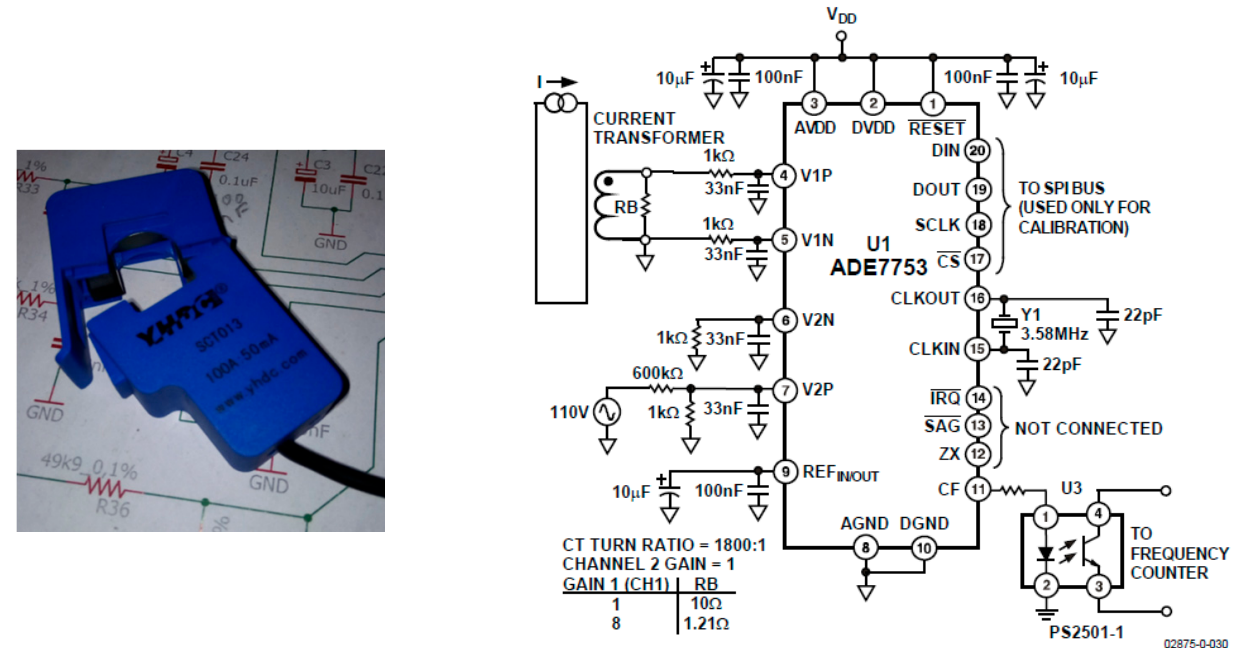

Figure 5. The integrated circuit ADE7753 measures the AC electrical parameters, and the sensor SCT-013 is the current transformer.

Using its programming, the acquired signals can be processed and the calculations performed in order to estimate the energy provided by the inverter and to store these energy data in different registers. In order to provide proper measurements, a voltage transformer with galvanic isolation and antialiasing filters is incorporated in order to remove high-frequency signals.

Table 2 shows a classification of the sensors used, indicating the type of signal conditioning carried out to adapt its output signal to the input of the data acquisition system used. 
Table 2. Sensors used and classification.

\begin{tabular}{ccc}
\hline $\mathbf{P}$ & Type & Signal Conditioning \\
\hline In-plane irradiance $(\mathrm{POA})\left(\mathrm{G}_{\mathrm{i}}\right)$ & Digital & Logic \\
Ambient temperature $\left(\mathrm{T}_{\mathrm{amb}}\right)$ & Digital & Direct connection \\
Array voltage $\mathrm{DC}\left(\mathrm{V}_{\mathrm{A}}\right)$ & Analog & Physic \\
Array current DC $\left(\mathrm{I}_{\mathrm{A}}\right)$ & Analog & Logic \\
Electrical parameters AC & Analog & Physic-Logic \\
\hline
\end{tabular}

In order to choose the data acquisition system (DAS), proposals by other authors in this field have been taken into account, such as the aforementioned experiments $[16,18,30]$ in which photovoltaics system monitoring was based on low-cost data acquisition systems. The monitoring of meteorological and electrical parameters in a photovoltaic stand-alone system pumping station was studied by A Mahjoubi [21]. Temperature monitoring in applications related to solar energy was developed by H.E. Gad and Hisham. E. Gad [48]. Remote monitoring solutions, proposed by H. R. Iskandar for PVSs, provide an online application for the acquisition, recording and analysis of electrical parameters of a PVS [49]. We can also observe the DAS proposed by S. Fanourakis et al. (2017) for the monitoring of photovoltaic stand-alone systems, which performs the measurement of electrical parameters of the PVS (the voltage and current of the PVG, the battery and the loads), as well as those of the battery temperature and state of charge. This DAS works in parallel with another DAS that records data on the main faults of the grid. The information obtained by both systems is used for the maintenance of the PVS [19].

Table 3 summarizes the different characteristics of the low-cost systems used by other authors to monitor photovoltaic systems. It has been determined whether the monitoring systems follow the requirements and recommendations of the standard IEC61724-1 and whether IoT has been used in order to store and analyze the performance of the monitored photovoltaic system.

Table 3. Comparison the potential solutions of monitoring system. DAS: data acquisition system.

\begin{tabular}{cccccc}
\hline Based on & $\mathbf{P}_{\mathbf{A}}$ & DAS & Data Storage & Connection & $\begin{array}{c}\text { Standard } \\
\text { IEC61724-1 }\end{array}$ \\
\hline Prototype & $555 \mathrm{~W}$ & Arduino Mega & IoT & Internet & Achive \\
{$[30]$} & $1 \mathrm{~kW}$ & DAS based on 16F877 & SMS & GPRS/GSM & No comment \\
{$[18]$} & $150 \mathrm{~W}$ & Arduino Uno & Card SD & No possible & Achive \\
{$[48]$} & No comment & Arduino Mega & Card SD & No possible & No comment \\
{$[49]$} & $1.6 \mathrm{kWp}$ & Arduino Uno & Card SD & Via radio & No comment \\
{$[16]$} & $2.2 \mathrm{~kW}$ & Arduino Uno & No Comment & GPRS/Web & No comment \\
{$[21]$} & No comment & Arduino Uno & SMS & GPRS & No comment \\
{$[19]$} & No comment & Arduino Nano & Card SD & No possible & No comment \\
\hline
\end{tabular}

Concerning the DAS, it must be noted that the main element of this block is the Arduino MEGA 2560 data acquisition card (DAC), which is a very low-cost card. Furthermore, we can find a large amount of documentation on monitoring projects, such as the one presented in [18] for the design of a monitoring system for PVS. Another element of the DAS is a real-time clock (RTC) model, DS1307. This device is connected via the $\mathrm{I}^{2} \mathrm{C}$ communications bus (inter-integrated circuit) to the Arduino card to control the sampling time, which in this case is $1 \mathrm{~min}$ for all the measured parameters. In order to view the monitored parameters in situ, an LCD display is included, which is connected via the $\mathrm{I}^{2} \mathrm{C}$ bus. This device has been programmed to show the value of the measured parameters every $20 \mathrm{~s}$.

In order to manage the communication, an Arduino Ethernet Shield has been applied to enable communication via the Ethernet, connecting to a local network socket and to the DAC via the Serial Peripheral Interface (SPI) bus. This hardware allows communication between the Arduino Mega 2560 DAC and the channel created on the IoT platform. 
The connection and installation of the elements of the system have been performed with electrical equipment in water-tight conditions (Figure 6).

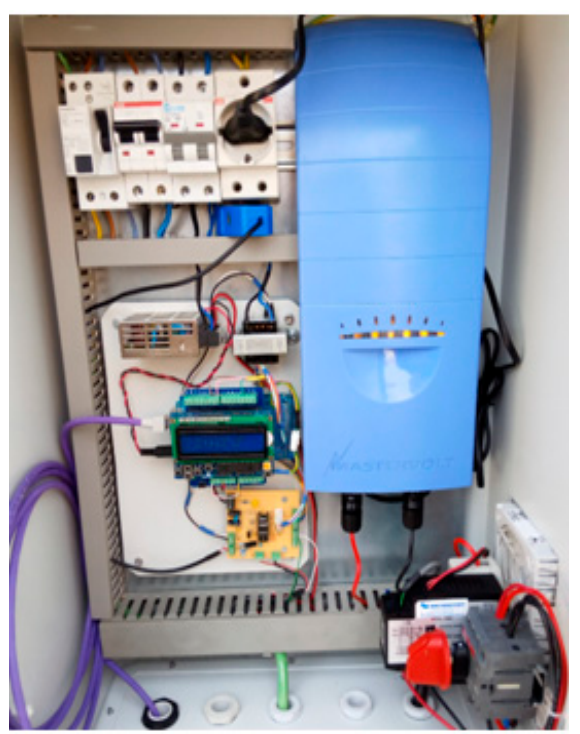

Figure 6. Electrical equipment.

The main objective of the prototype is to monitor in real-time the performance of a photovoltaic self-consumption system. To achieve this goal, the proposed methodology is summarized in the flowchart shown in Figure 7.

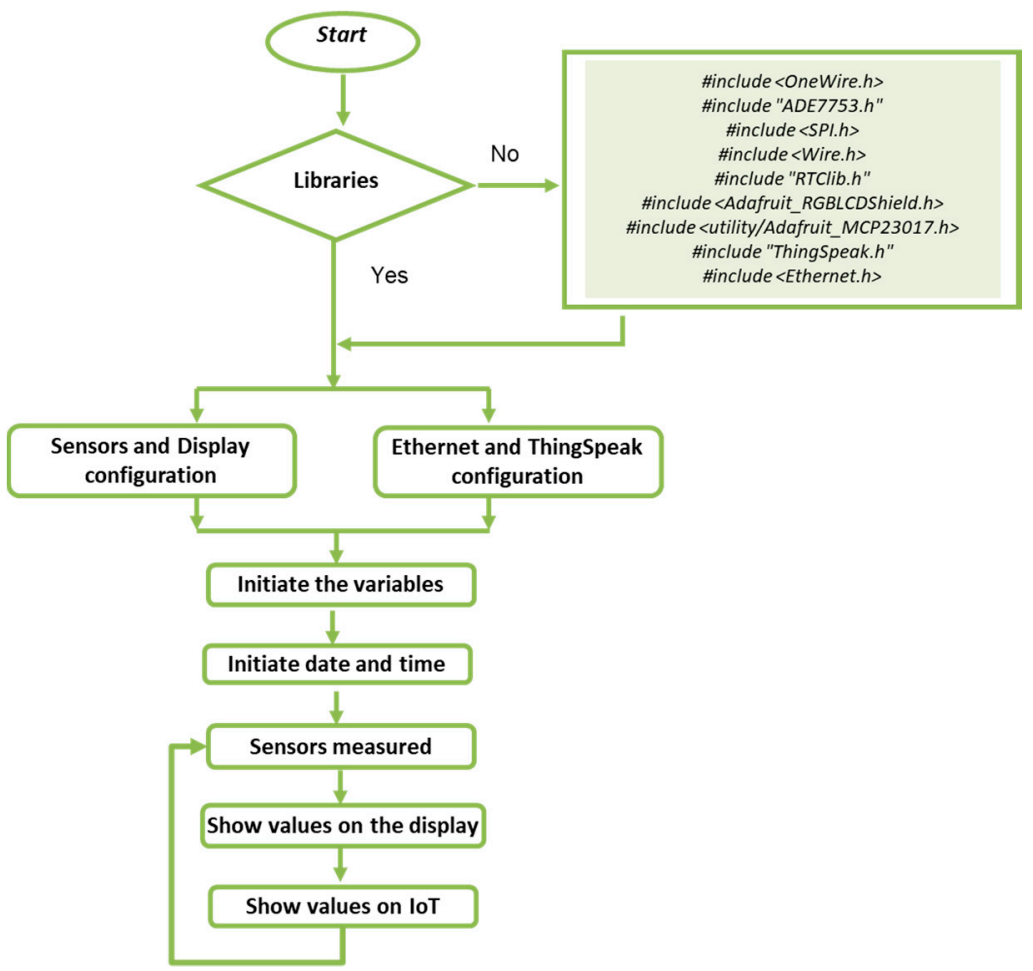

Figure 7. Flowchart of prototype monitoring a photovoltaic self-consumption system.

Figure 7 shows how the developed prototype takes measurements, verifies the connection between the system and the IoT address and visualizes the measured data on the thingspeak of the prototype when monitoring a photovoltaic self-consumption system. 


\subsection{Study of Uncertainty}

The standard uncertainty $u\left(\mathrm{x}_{\mathrm{i}}\right)$ can be evaluated through the possible variability. When it is evaluated in this way, it is called a Type B standard uncertainty. In determined cases where there is no specific knowledge about the possible values of the input quantities, it can be assumed that there is an equal probability for the input quantities. Therefore, a rectangular distribution of possible values can be assumed. In this case, the standard uncertainty can be estimated as

$$
u=\frac{a}{\sqrt{3}}
$$

where $\mathrm{a}$ is the semi-range between lower and lower limits.

The standard uncertainty of the measurand is obtained by combining the standard uncertainties and is known as the combined standard uncertainty, which is denoted by $u_{c}$. The combined standard uncertainty is the positive square root of the sum of each estimated variance [50]:

$$
u_{c}=\sqrt{\sum_{i} u_{i}^{2}}
$$

Uncertainty values of each measurand are estimated following the recommendations of the standard.

The value of the uncertainty corresponding to the photovoltaic generator voltage $\left(\mathrm{V}_{\mathrm{A}}\right)$ depends on both the IAMA module and the analog input of the Arduino Mega. The IAMA module is a configurable universal signal-conditioning module. IAMA monitors the input voltage and provides a linearly proportional voltage output. It has been configured with a voltage input range of $0-100 \mathrm{~V}$ and an output voltage range of $0-5 \mathrm{~V}$. The module accuracy, including linearity, has a value of $0.1 \%$ of the selected voltage range at full scale [44]. Therefore, the uncertainty associated with the IAMA module is $\pm 0.058 \%$. On the other hand, the output of the IAMA module is directly connected to an analog input of the Arduino Mega 2560 card with 10 bit resolution and 1024 different available codes. The resolution would be $0.098 \mathrm{~V}$; therefore, the standard uncertainty associated with $\mathrm{V}_{\mathrm{A}}$ is \pm 0.081 .

There are two factors in the photovoltaic generator current measurement: the hall-effect transducer and the analog input of Arduino card. The ACS714 sensor is used to measure $\mathrm{I}_{\mathrm{A}}$ with a range between $-30 \mathrm{~A}+30 \mathrm{~A}$. The total percentage error of the current measurement is $\pm 5 \%$ [43] over an ambient temperature range of $-40^{\circ} \mathrm{C}$ to $150^{\circ} \mathrm{C}$. In this sense, the uncertainty associated with the integrated circuit is $\pm 2887 \%$. Similarly, to $V_{A}$, the output voltage which is provided by ACS714 sensor is applied to another analog input of Arduino Mega 2560. In this case, the resolution per code is $0.059 \mathrm{~A}$ and the standard uncertainty of the analog input is $\pm 0.056 \%$. The combined uncertainty associated of $\mathrm{I}_{\mathrm{A}}$ is $\pm 2887 \%$ for a full ambient temperature range. However, when the ambient temperature is $25^{\circ} \mathrm{C}$, the total output error of the integrated ACS714 is $\pm 1.5 \%$ and the associated standard uncertainty is $\pm 0.87 \%$. The combined uncertainty of $\mathrm{I}_{\mathrm{A}}$ is $\pm 0.86 \%$ for $25^{\circ} \mathrm{C}$ of ambient temperature.

In the case of $\mathrm{P}_{\mathrm{A}}$ uncertainty, it can be calculated as the combined uncertainty of the error corresponding to both the generator current and the generator voltage. In this sense, the uncertainty obtained is $\pm 2888 \%$.

An integrated ADE7753 circuit is used to estimate the root mean square (RMS) AC voltage and current. A voltage divider circuit with two resistors is required in order to measure the AC voltage. The resistors have a tolerance of $0.1 \%$, and the RMS voltage measurement error provided by the integrated circuit is $0.5 \%$ [46]. As a result, the combined uncertainty of $V_{\text {out }}$ has a value of $\pm 0.090 \%$. On the other hand, alternating current measurement also requires a current transformer. A hall-effect sensor, SCT-013T, was used as a current transformer. This sensor has a non-linearity error of $\pm 3 \%$ [45], and the standard uncertainty has a value of $1.73 \%$. Moreover, the output signal of SCT-013T goes through a resistor $\left(R_{B}\right)$ where the current is converted into voltage. Then, the voltage is measured by the multifunction meter, ADE 7753 , of analog devices. The resistance has a tolerance of $0.1 \%$; therefore, 
the uncertainty is $\pm 0.058 \%$. The multifunction metering circuit has a current RMS error of $0.5 \%$ [46]. Therefore, the combined uncertainty associated with measuring $\mathrm{I}_{\mathrm{out}}$ is $\pm 1.85 \%$.

The $\mathrm{P}_{\text {out }}$ uncertainty may be estimated as the combined uncertainty of $\mathrm{I}_{\text {out }}$ and $\mathrm{V}_{\text {out }}$, but also another error source should be added. This error is due to the phase error between channels when different analog inputs (current and voltage) are used in the integrated ADE7753 circuit. The maximum value of the phase error between channels is $\pm 0.05 \%$. The standard uncertainty is $\pm 0.029 \%$. The combined uncertainty for $\mathrm{P}_{\text {out }}$ has a value of $2.55 \%$.

The integrated circuit ADE7753 has been used to measure the output energy ( $\left.E_{\text {out }}\right)$. This integrated circuit supports the requirements of standard 62053-22 for class $0.5 \mathrm{~S}$. This is the requirement indicated by the standard for energy monitoring.

Finally, as a summary, the required uncertainty requirements of the electrical measurements at the inverter level are shown in Table 4.

Table 4. Study of uncertainty.

\begin{tabular}{|c|c|c|c|c|}
\hline Parameter & Symbol & Class B & Class C & Uncertainty of Prototype \\
\hline Generator voltage (DC) & $\mathrm{V}_{\mathrm{A}}$ & - & - & $\pm 0.081 \%$ \\
\hline Generator current (DC) & $\mathrm{I}_{\mathrm{A}}$ & - & - & $\pm 2.887 \%$ \\
\hline Generator power (DC) & $\mathrm{P}_{\mathrm{A}}$ & - & - & $\pm 2.888 \%$ \\
\hline Output voltage (AC) & $V_{\text {out }}$ & $3 \%$ & - & $\pm 0.090 \%$ \\
\hline Output current (AC) & $I_{\text {out }}$ & $3 \%$ & - & $\pm 1.85 \%$ \\
\hline Output power (AC) & $\mathrm{P}_{\text {out }}$ & $3 \%$ & - & $\pm 2.55 \%$ \\
\hline Output energy & $E_{\text {out }}$ & Class 0.5 S IEC $62053-22$ & Class 2 IEC 62053-21 & Class 0.5 S IEC 62053-22 \\
\hline
\end{tabular}

\section{Experimental Results and Discussion}

This section shows the operation of the monitoring prototype and the IoT channel for the aforementioned photovoltaic self-consumption system. Currently, there are numerous open-access IoT platforms. Although all of them allow the storage of data in real time, the one chosen in the proposed monitoring system is thingspeak, due to its compatibility with the data acquisition system used and for its possibilities for the analysis and visualization of the data through Matlab. In the study carried out by Abdul-Rahman and Graves, this platform is used for the monitoring of different parameters of interest inside a home [43]. The graphical interface is intuitive and simple, with a modular design that allows new graphics and/or indicators to be displayed depending on the type of end-user. Access can be restricted so that a user and password are required. However, in our case, anyone can access the system if the channel's web address is known (https://thingspeak.com/channels/264843).

If the channel is accessed with the administrator profile, all stored data can be accessed and selected parameters from the monitored ones can be displayed. The rest of the users can visualize the public parameters and obtain the file with the most recent data (Figure 8).

31-Oct-2019 12:57:05

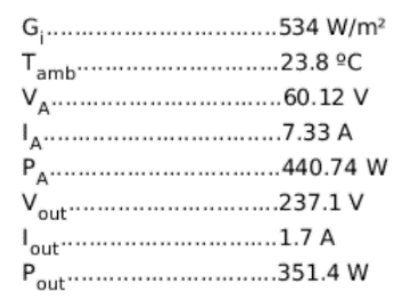

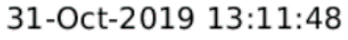

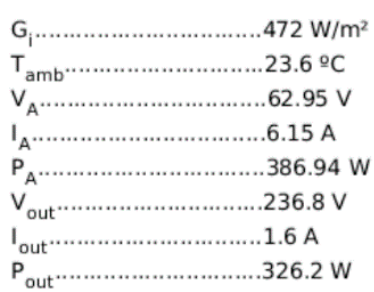

Figure 8. Channel of the Internet of Things (IoT) on thingspeak. Display of instantaneous values.

Two graphs are also shown with the output power of the PVS $\left(\mathrm{P}_{\mathrm{A}}\right)$ and with the active alternating power generated ( $\mathrm{P}_{\text {OUT }}$ ) on a September day (Figures 9 and 10, respectively). 


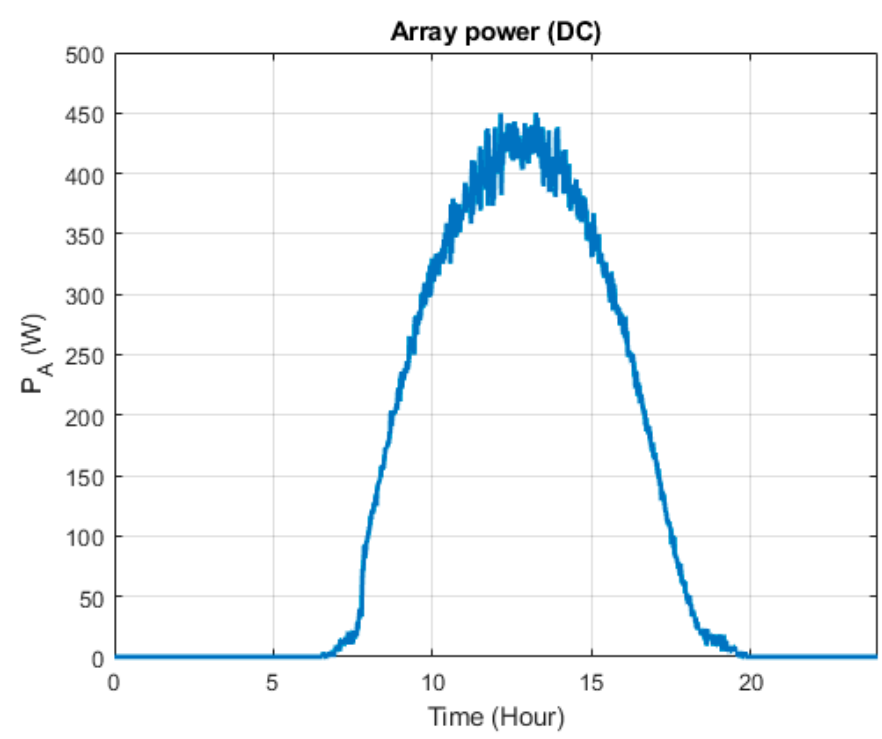

Figure 9. Array power, $\mathrm{P}_{\mathrm{A}}$ on a September day.

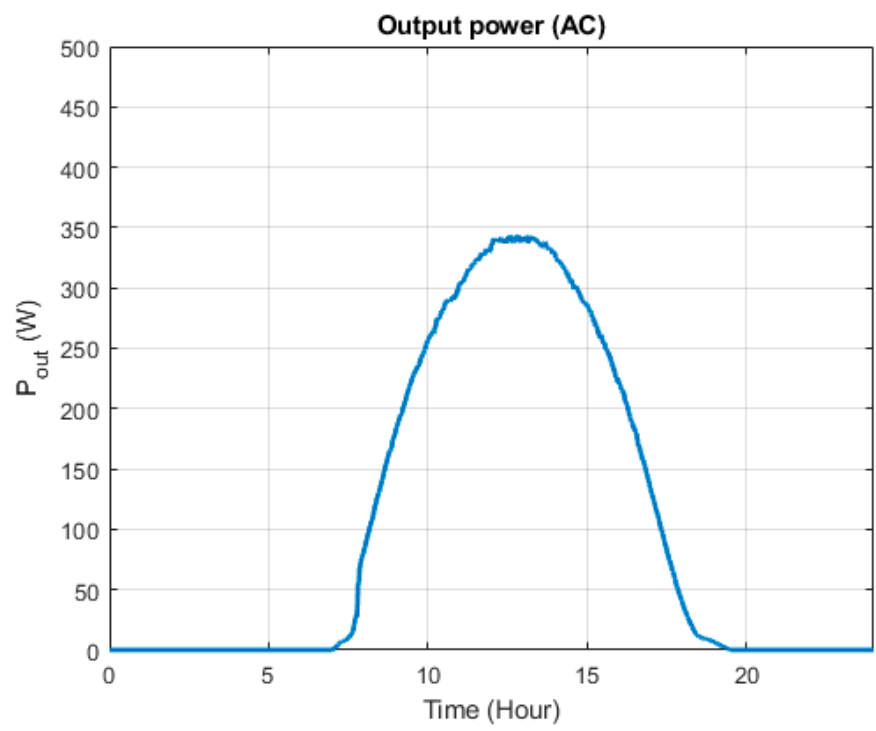

Figure 10. Output power, $\mathrm{P}_{\text {OUT }}$ on a September day.

In Figure 11, a column chart is shown with the energy generated $\left(E_{\text {out }}\right)$ daily, on a September day. To evaluate the operation of the inverter, the relationship between the powers, $P_{A}$ and $P_{\text {out }}$ is calculated, with which an average efficiency value of the inverter is obtained. Values are obtained from those of $90 \%$. 


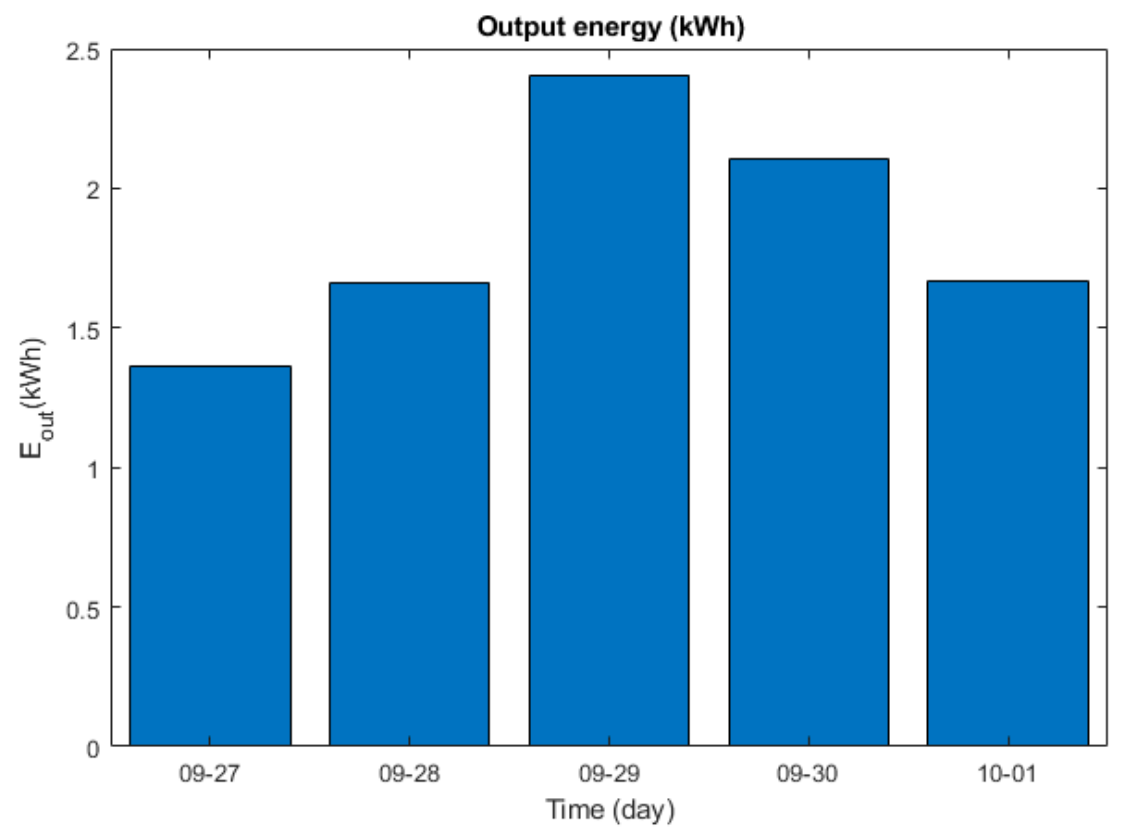

Figure 11. Energy generated ( $\left.\mathrm{E}_{\mathrm{OUT}}\right)$.

In addition to the above graphs, it is possible to download all the data acquired by the DAS. This data can be downloaded in the ".csv" format. Figure 12 shows daily monitored data $\left(G_{i}, T_{a m b}, V_{A}\right.$ and $\mathrm{I}_{\mathrm{A}}$ ) for a cloudy and sunny day.
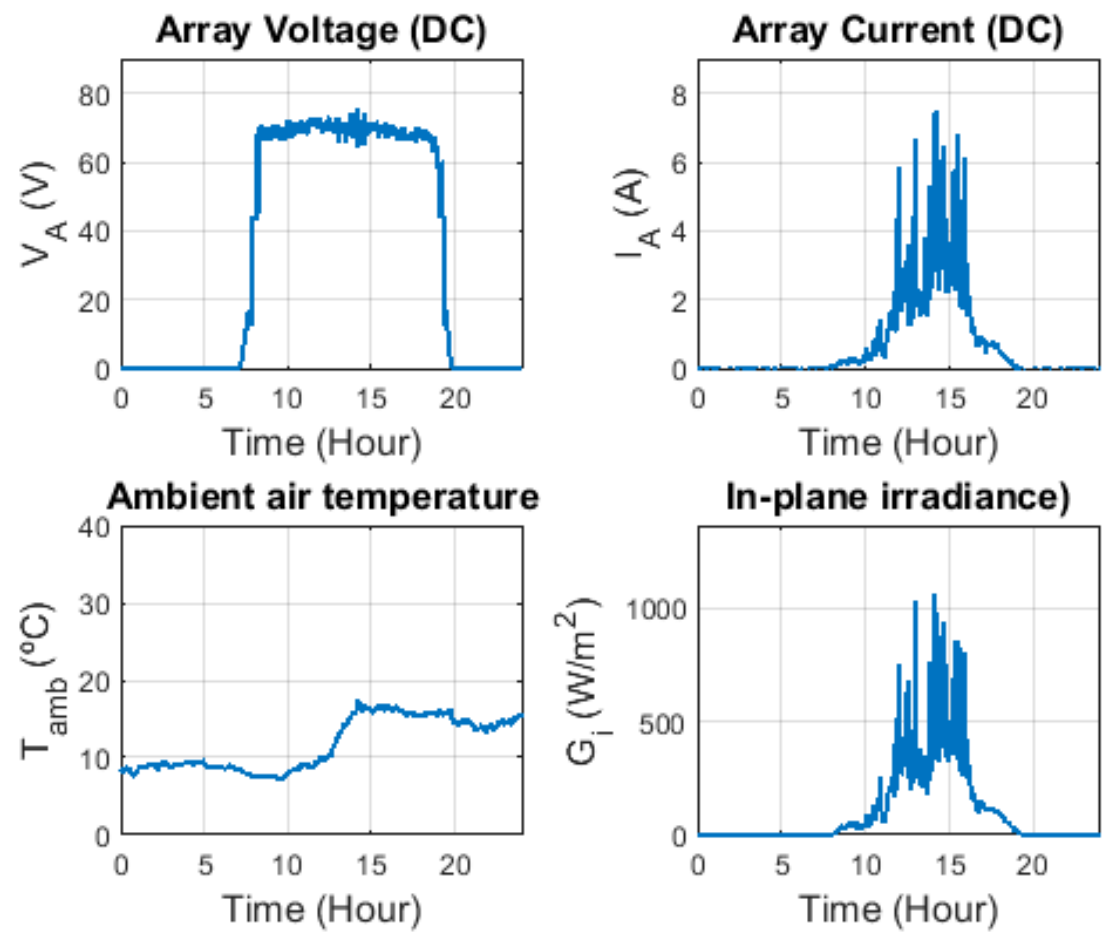

Figure 12. Cont. 

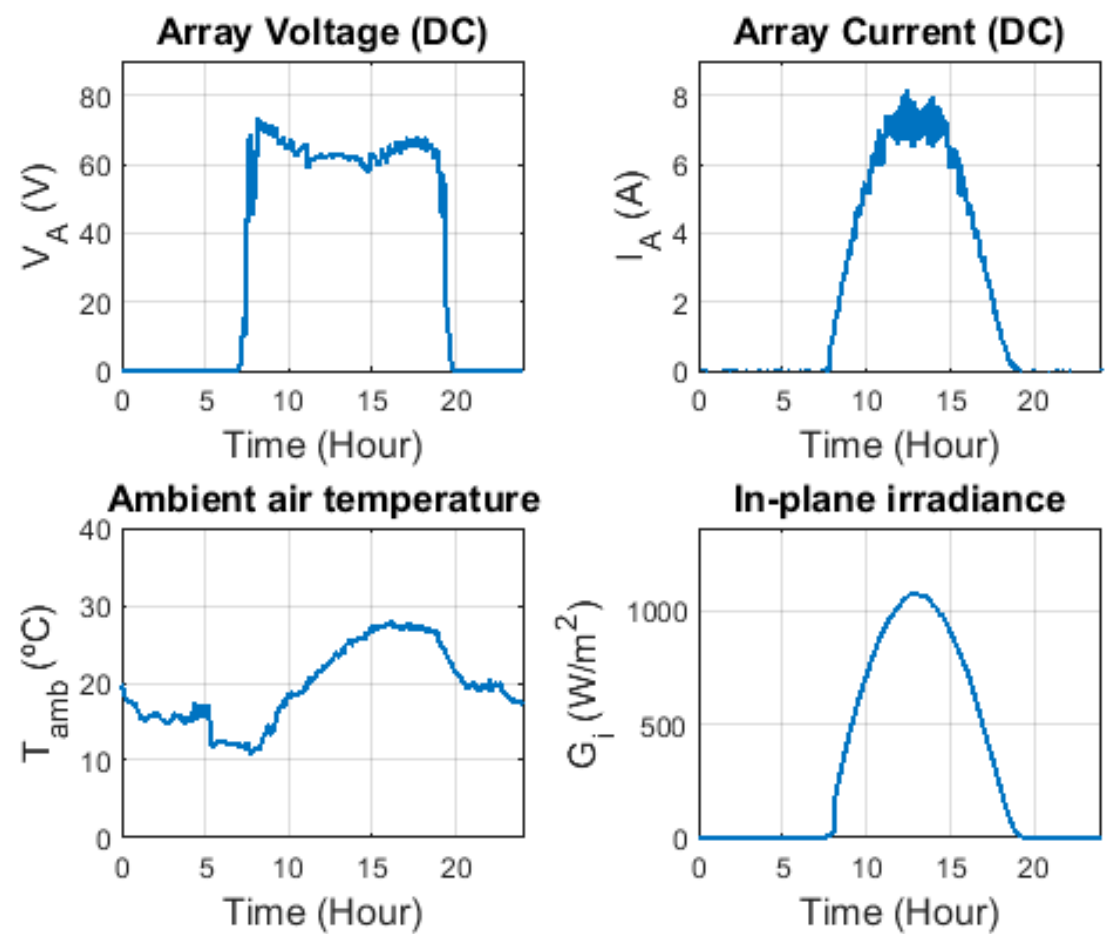

Figure 12. Monitored DC electrical parameters. Top, $G_{i}, T_{a m b}, V_{A}$ and $I_{A}$ on a cloudy day. Bottom, $V_{A}$ and $\mathrm{I}_{\mathrm{A}}$ on a sunny day.

For the sunny day, the current increases progressively from dawn to noon, at which time the maximum value is reached, which then decreases gradually until night falls. By contrast, on a cloudy day, many peaks caused by the increase of cloud cover are observed. As for the tension, on a sunny day, the value decreases around noon due to the effect of temperature, whereas on a cloudy day, where the temperature remained constant with very small variations, the voltage has a value of approximately $70 \mathrm{~V}$ from sunrise to sunset.

We also include two appendices which show the operation of the monitored prototype and the IoT channel for the photovoltaic self-consumption system. Appendix A shows the daily monitored data $\left(\mathrm{V}_{\mathrm{A}}, \mathrm{I}_{\mathrm{A}}, \mathrm{T}_{\mathrm{amb}}\right.$ and $\left.\mathrm{G}_{\mathrm{i}}\right)$ for a cloudy and a sunny day for each month from June 2017 to May 2018. In addition, Appendix $B$ shows daily monthly average values of $\mathrm{V}_{\mathrm{A}}, \mathrm{I}_{\mathrm{A}}, \mathrm{T}_{\mathrm{amb}}$ and $\mathrm{G}_{\mathrm{i}}$ from June 2017 to May 2018.

\section{Conclusions}

A new monitoring prototype for photovoltaic self-consumption systems that follows the recommendations of the IEC 61724-1 standard has been presented. This prototype provides not only measured but estimated parameters and gives a solution to the limitations of the physical memory size of hardware-software free platforms. In addition, Cloud computing allows real-time performance, allowing us to analyze PV systems according to the requirements in the IEC 61724-1 standard. Therefore, users have a ready tool at any time to learn the operating status of the PV system. The tool not only shows the measured parameters in the IoT channel, but it also provides estimated parameters from the measured ones concerning the performance of the photovoltaic system.

Two issues have been taken into account: the cost and the complexity of the system. The DAS cost should be proportional to the cost of the photovoltaic self-consumption systems, which are generally small or medium-size and the monitoring system should be easily installed and handled.

An Arduino card is proposed as a DAS because it has enough processing capacity, and a local computer for data storage is no longer necessary. In addition, the compatibility of Arduino's own 
programming, through the libraries of its working environment, with meteorological and electrical sensors from different manufacturers simplifies the assembly of monitoring systems for PVS.

An IoT platform is used to visualize and store the data, which allows, free of charge, an analysis of the performance of the PVS. The comparison of the results with those of other monitoring systems was very positive, with an uncertainty that complies with the IEC61724 standard. The user may learn about possible failures from any place and at any time, providing a quick solution to these problems. Moreover, the graphic interface allows the user to select graphs and indicators.

Finally, the modularity of the proposed monitoring system must be highlighted. It can be easily adapted with slight modifications to any type of PVS, such as photovoltaic stand-alone or photovoltaic grid-connected systems.

Author Contributions: All authors contributed equally to this work. All authors have read and agreed to the published version of the manuscript.

Funding: This research was funded by the Agencia Estatal de Investigación (AEI) and the Fondo Europeo de Desarrollo Regional (FEDER) aimed at the Challenges of Society (Grant No. ENE 2017-83860-R “Nuevos servicios de red para microredes renovables inteligentes. Contribución a la generación distribuida residencial").

Acknowledgments: The authors wish thank to the University of Jaen for the programme "Plan de Apoyo a la I+D+I 2014-2015. Prorrogado hasta 2016". We also would like to acknowledge anonymous reviewers for their kind and interesting comments, which have helped us to improve the manuscript.

Conflicts of Interest: The authors declare no conflict of interest.

\section{Appendix A}

Appendix A shows daily monitored data $\left(V_{A}, I_{A}, T_{a m b}\right.$ and $\left.G_{i}\right)$ for a cloudy and a sunny day for each month from June 2017 to May 2018. 
14-Jun-2017
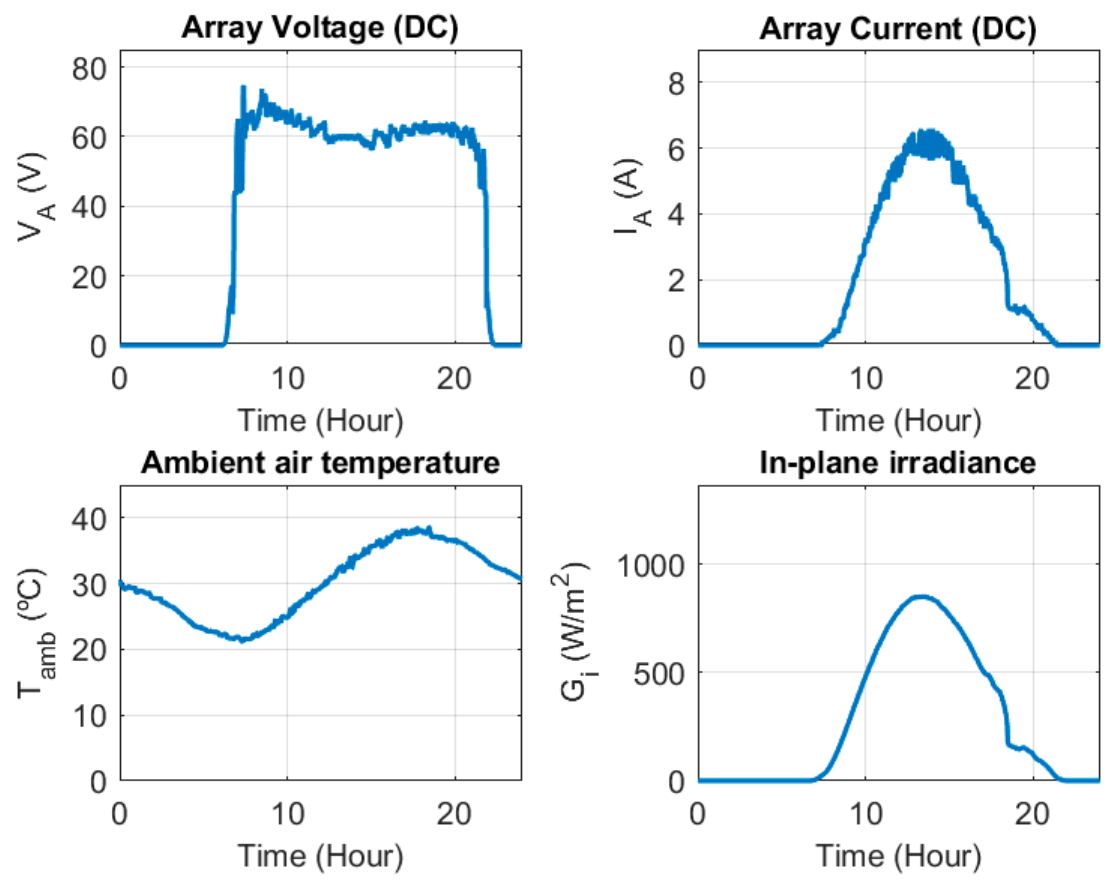

25-Jun-2017
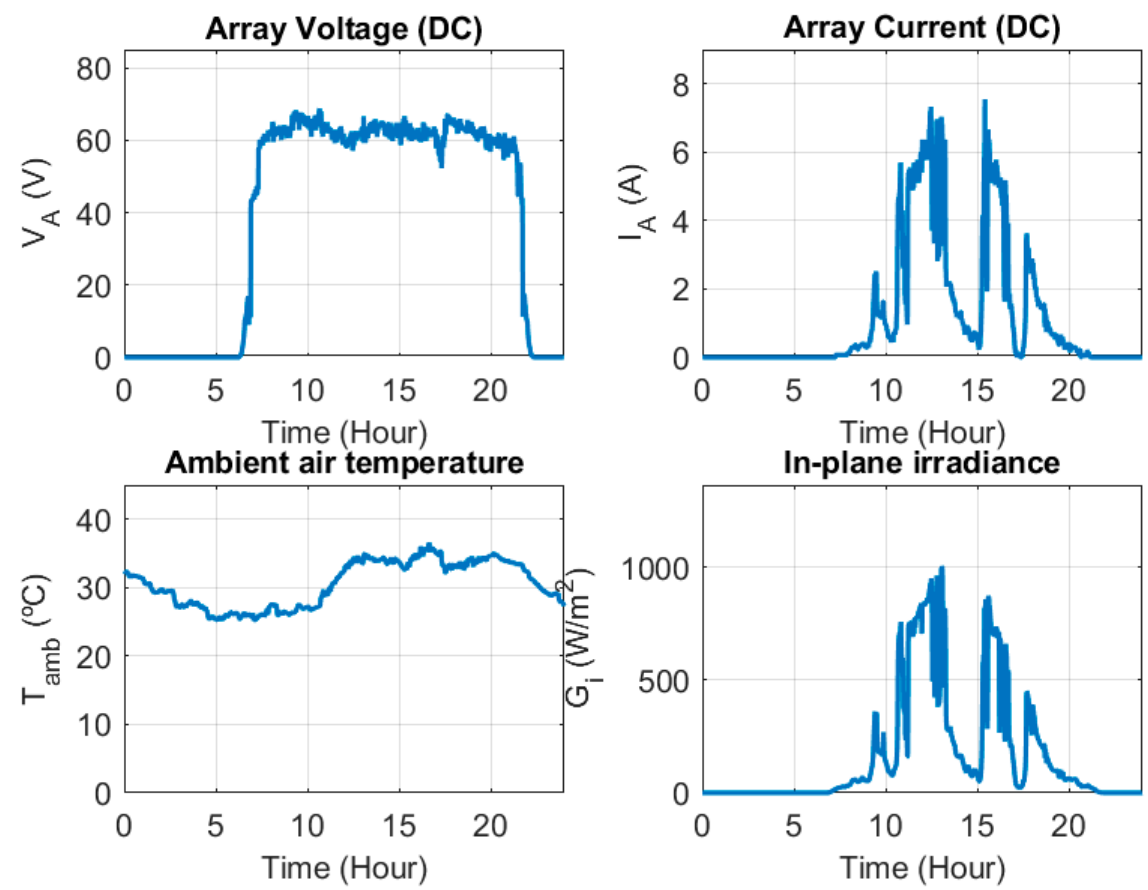

Figure A1. Cont. 
06-Jul-2017
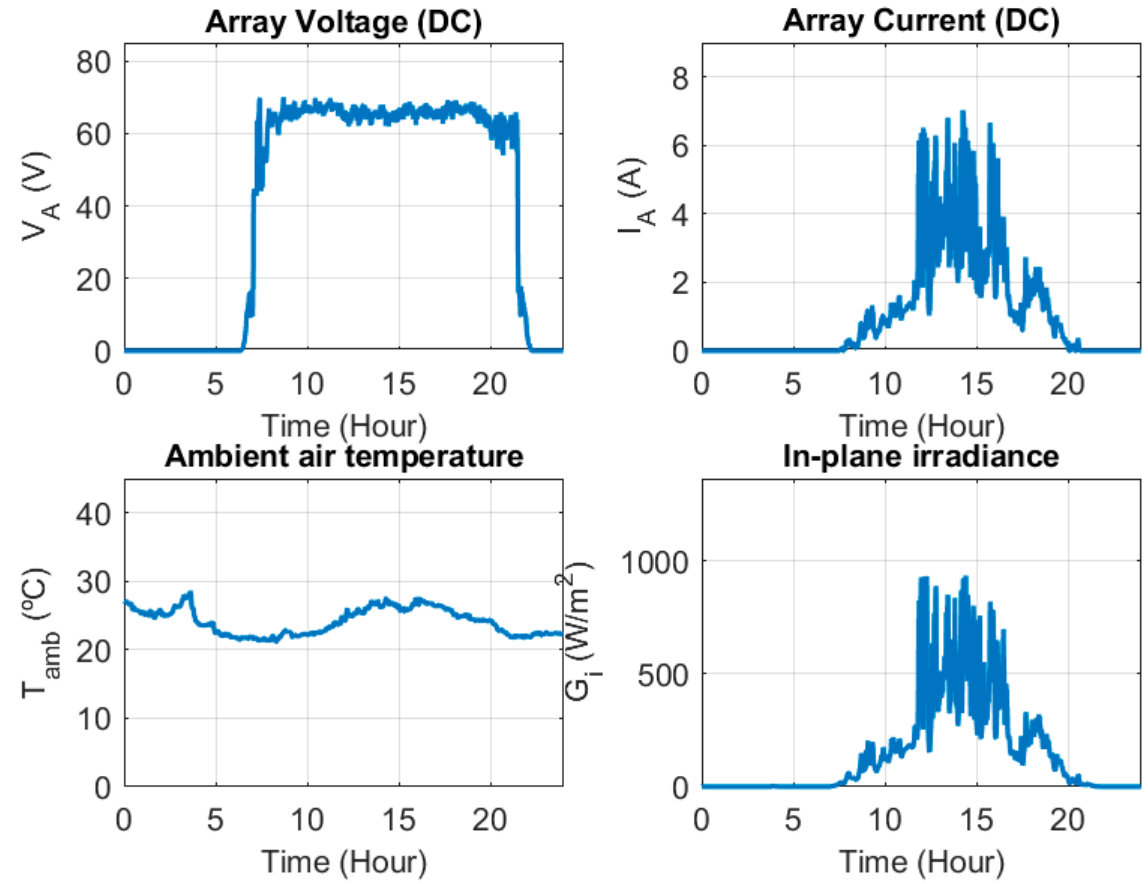

16-Jul-2017
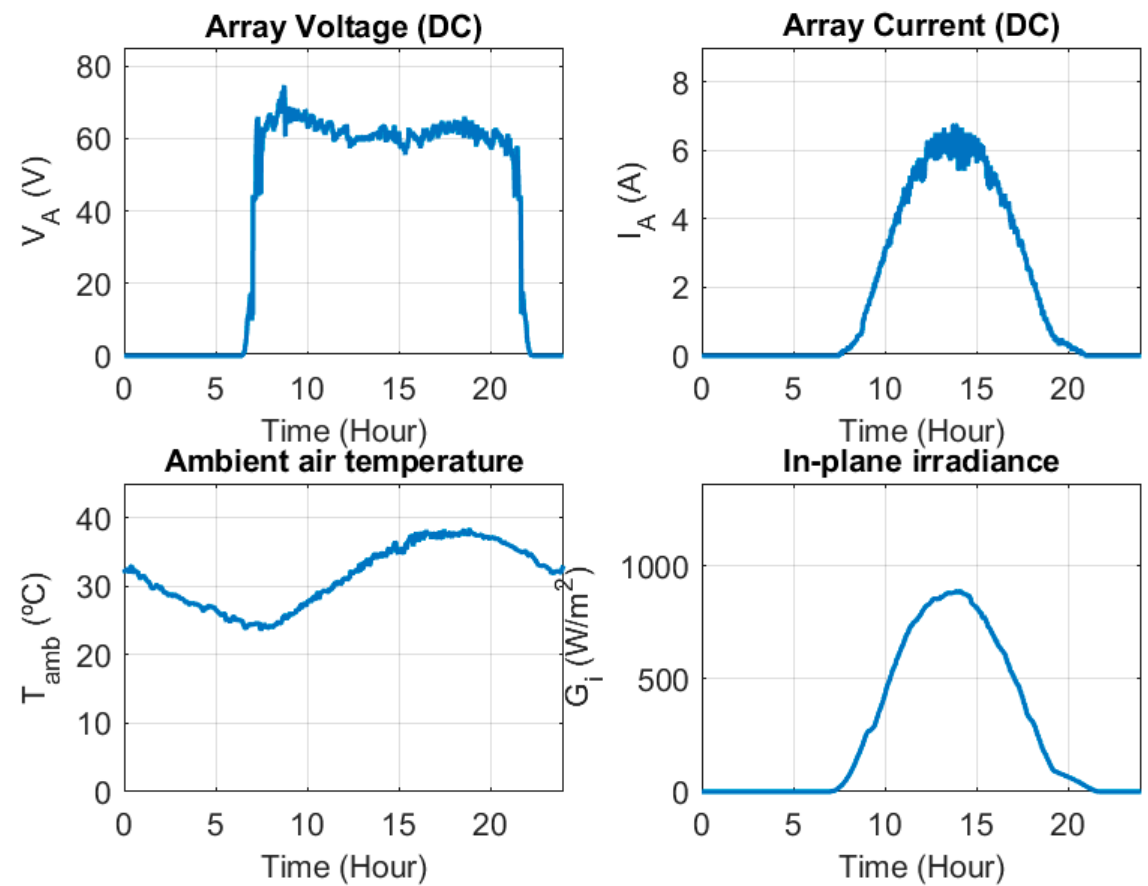

Figure A1. Cont. 
14-Aug-2017
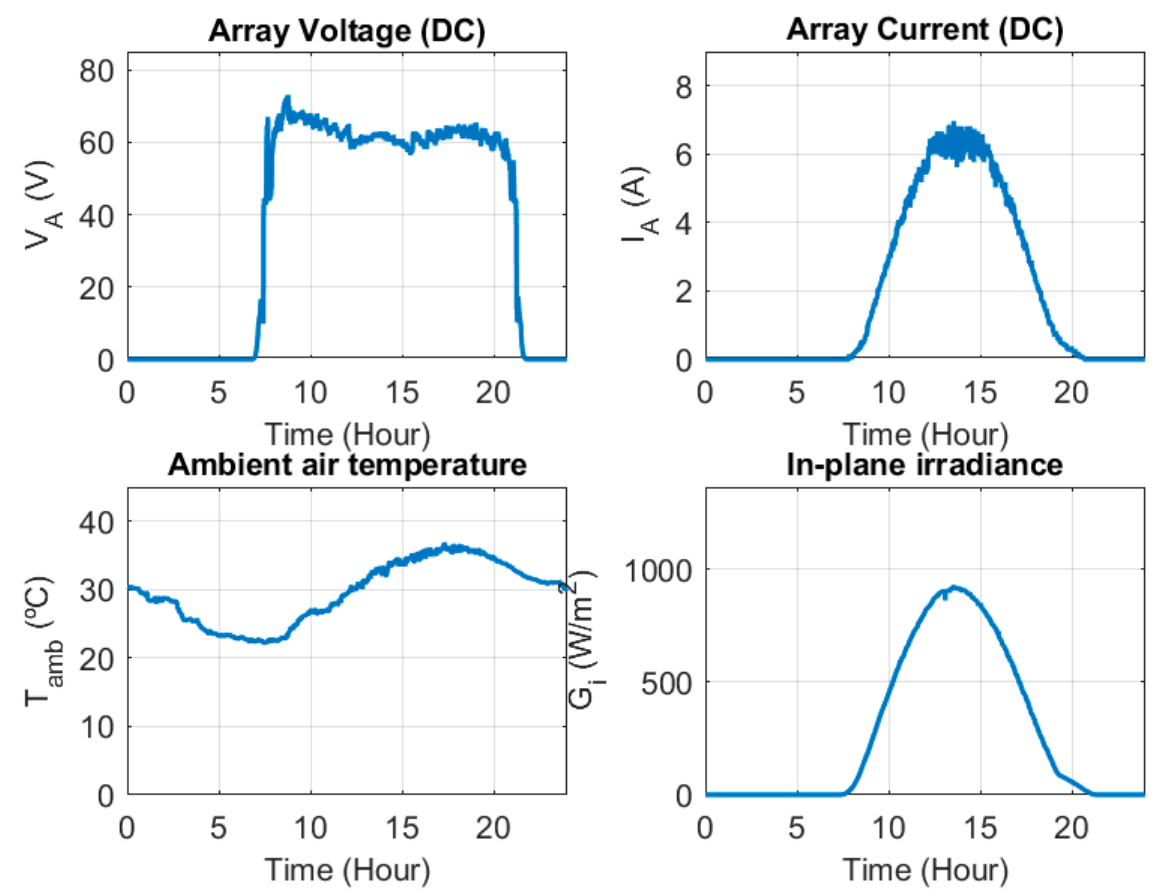

26-Aug-2017
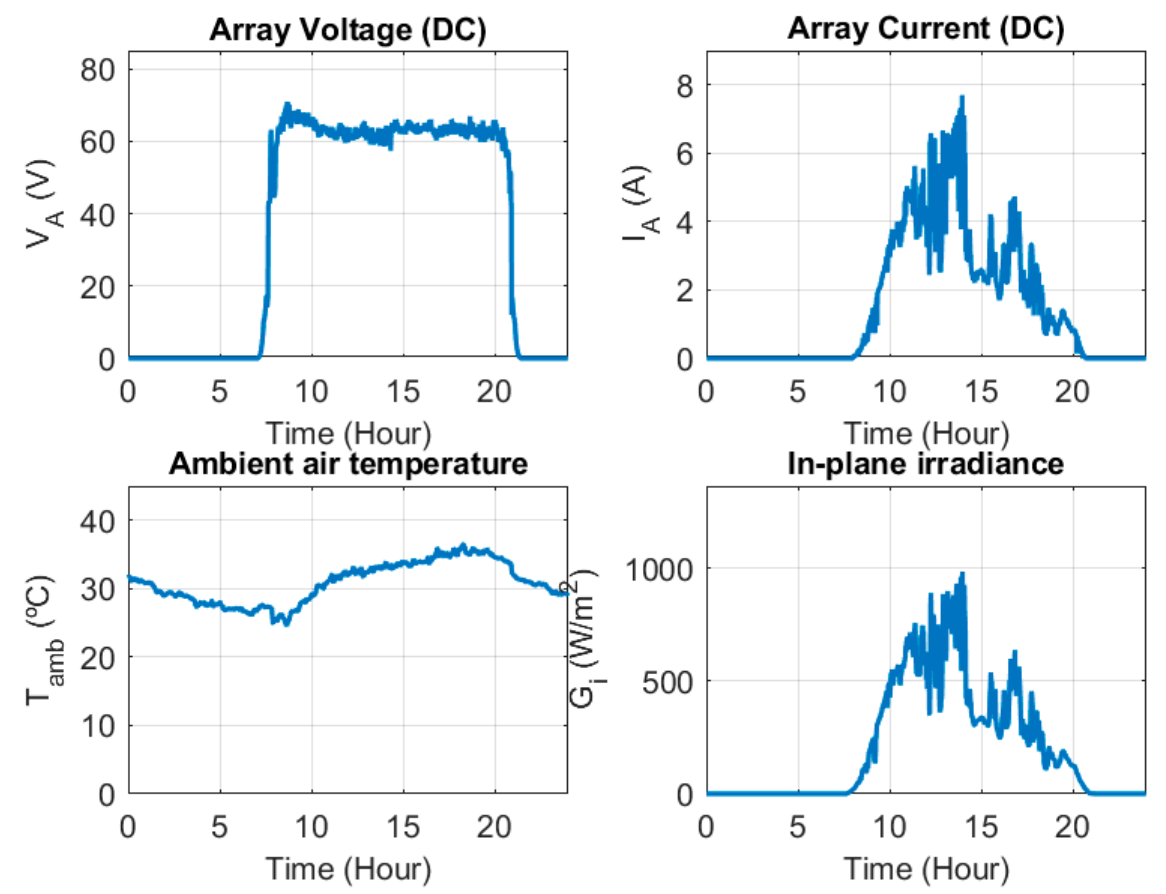

Figure A1. Cont. 
16-Sep-2017
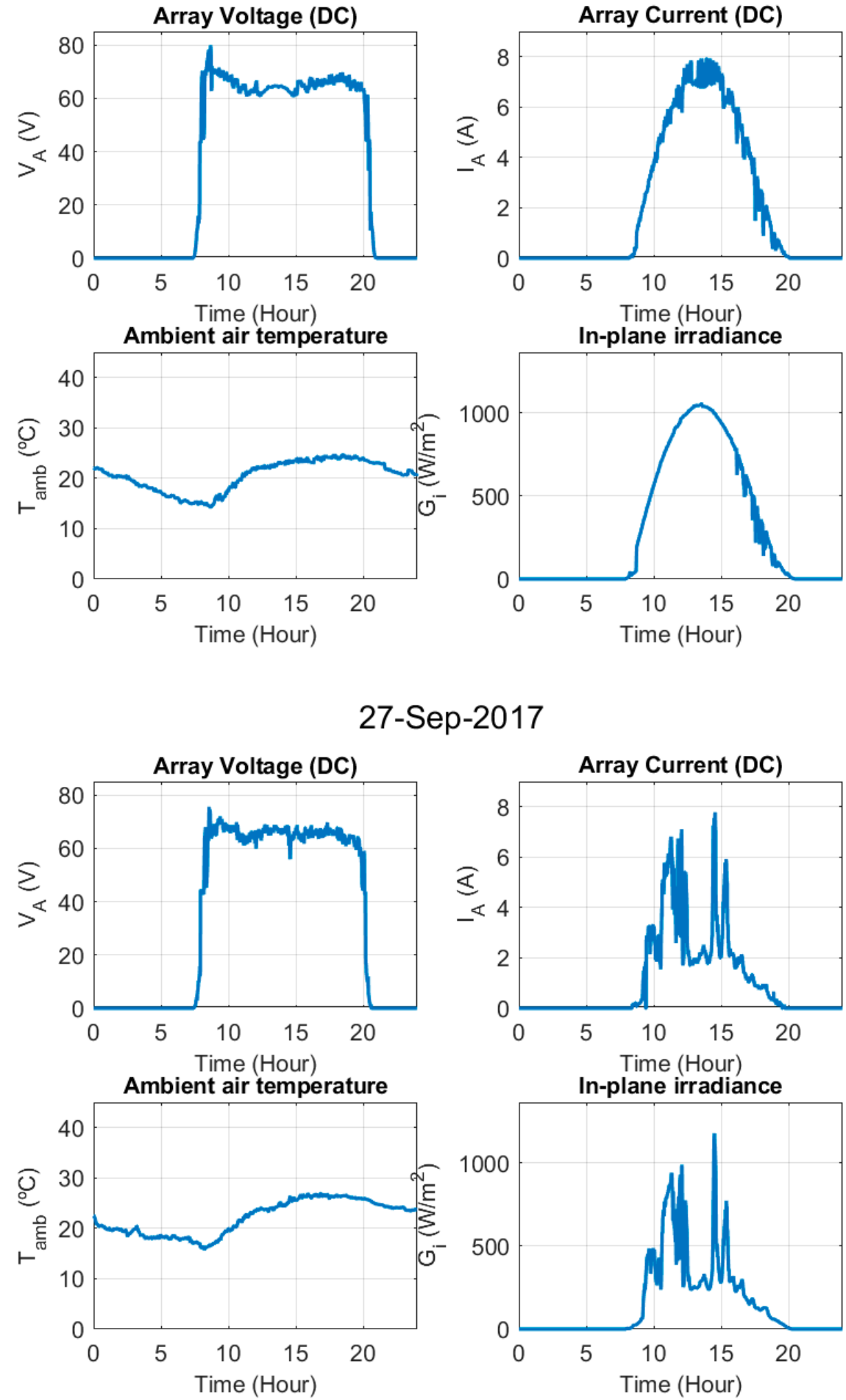

Figure A1. Cont. 
14-Oct-2017
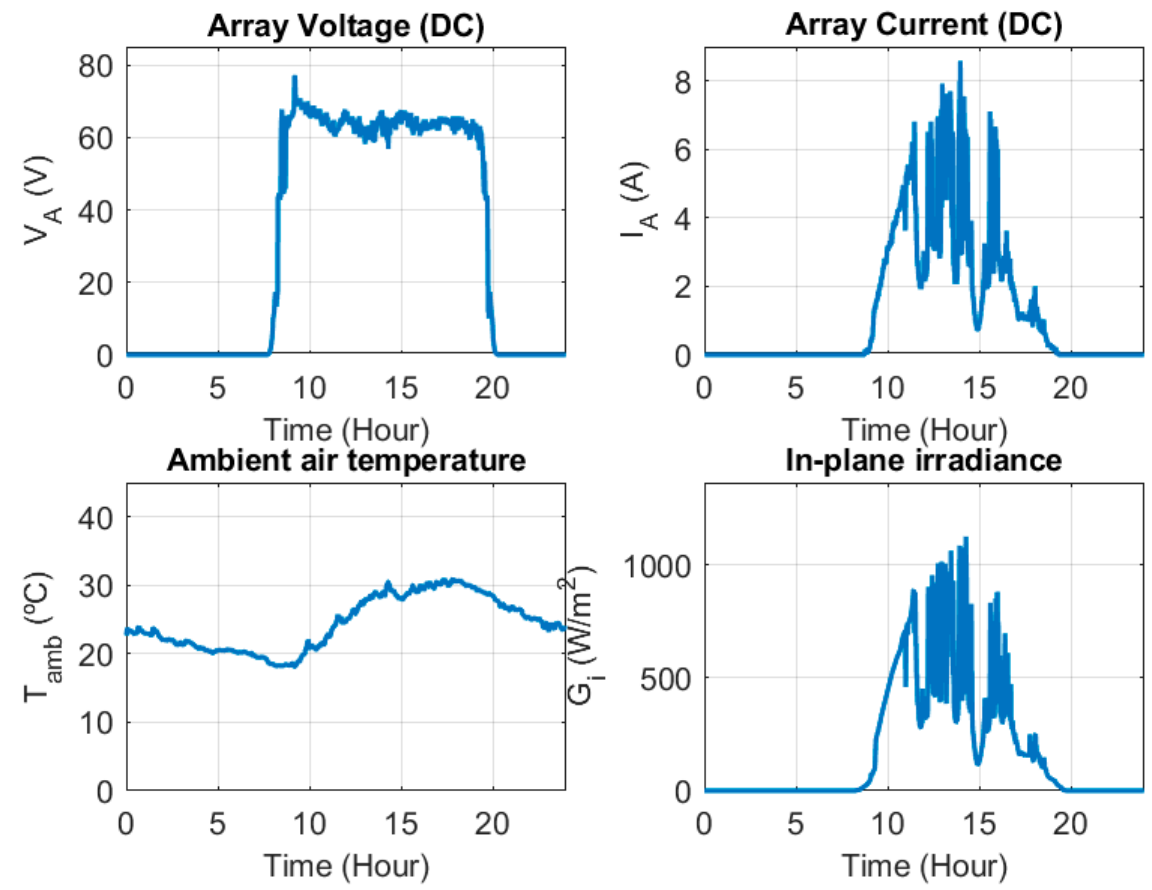

16-Oct-2017
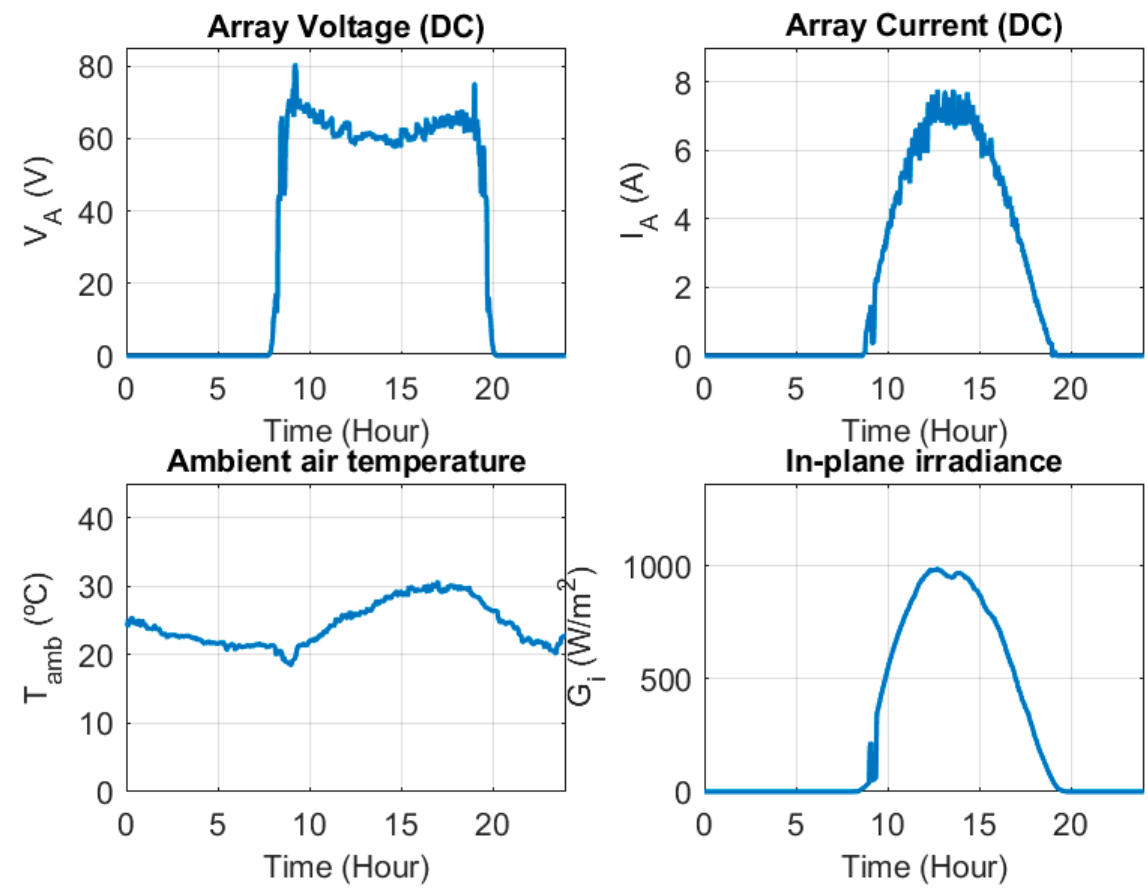

Figure A1. Cont. 

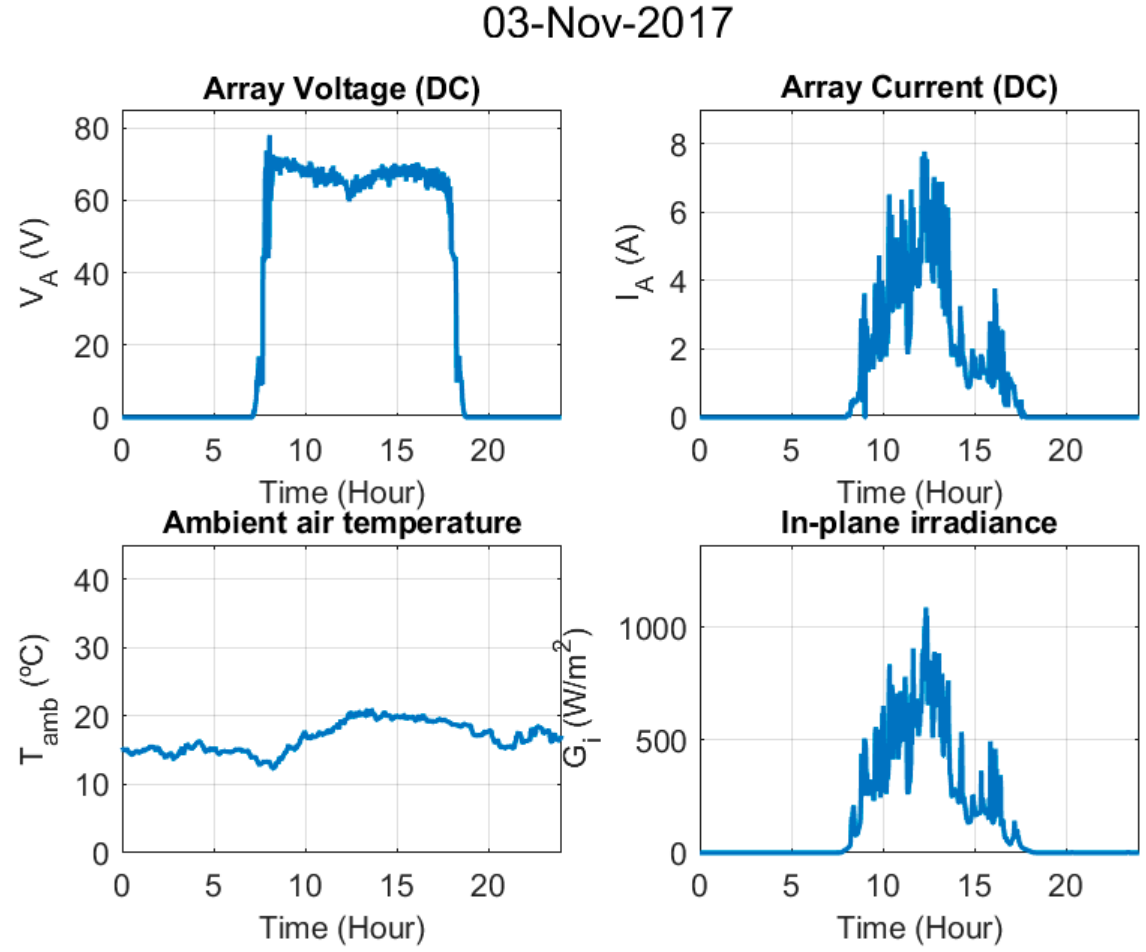

\section{6-Nov-2017}
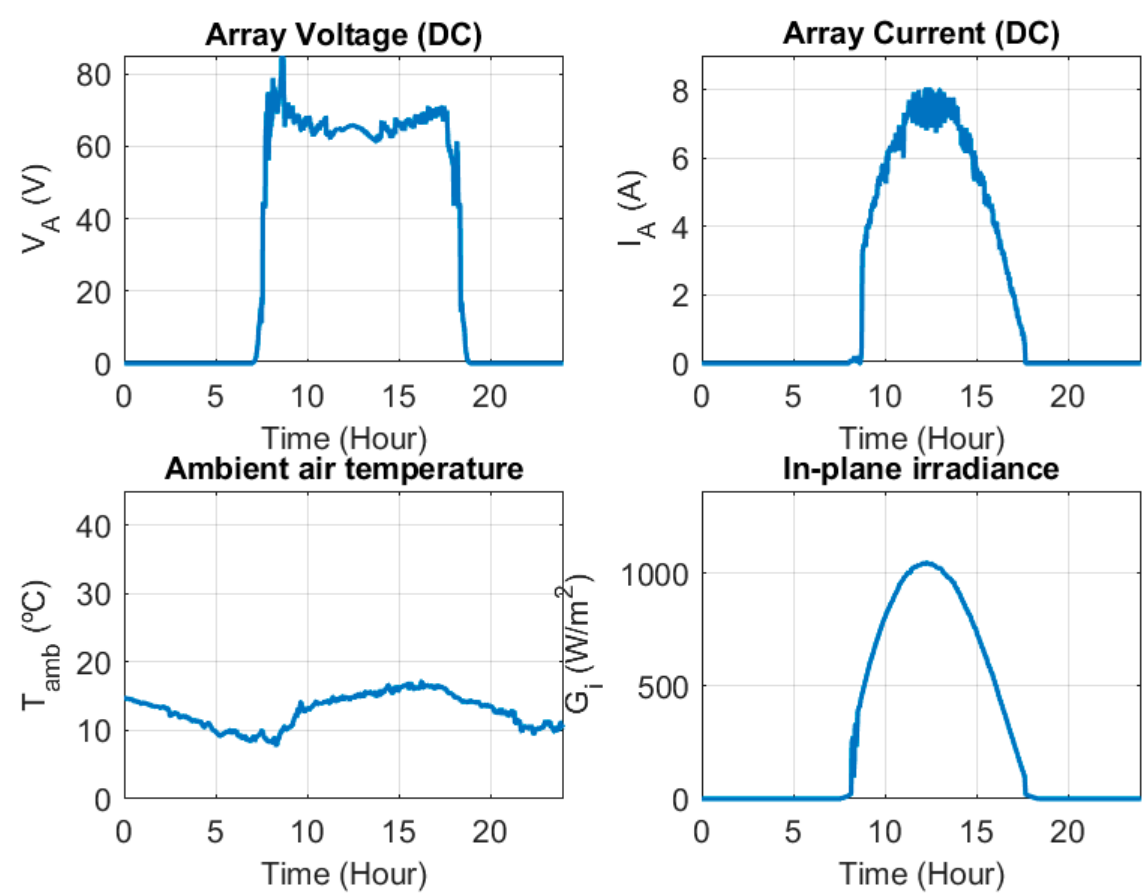

Figure A1. Cont. 
24-Dec-2017
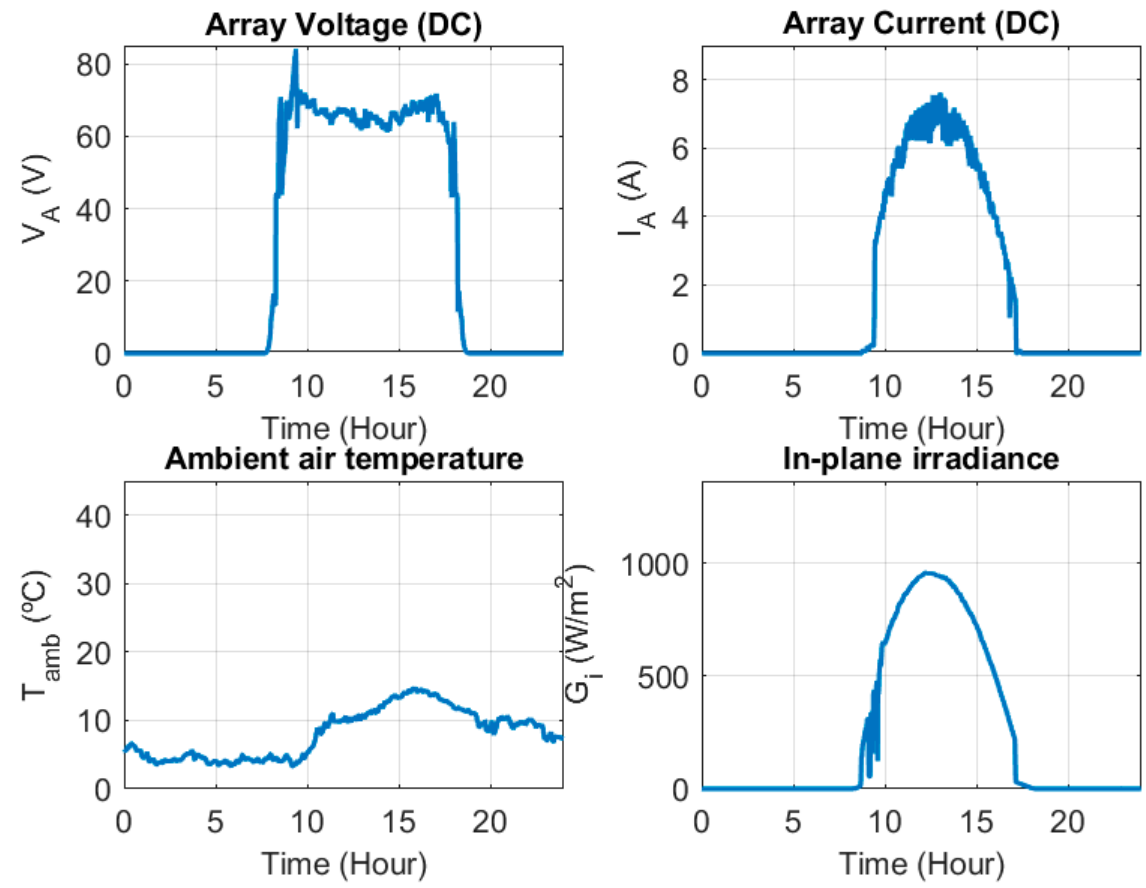

31-Dec-2017
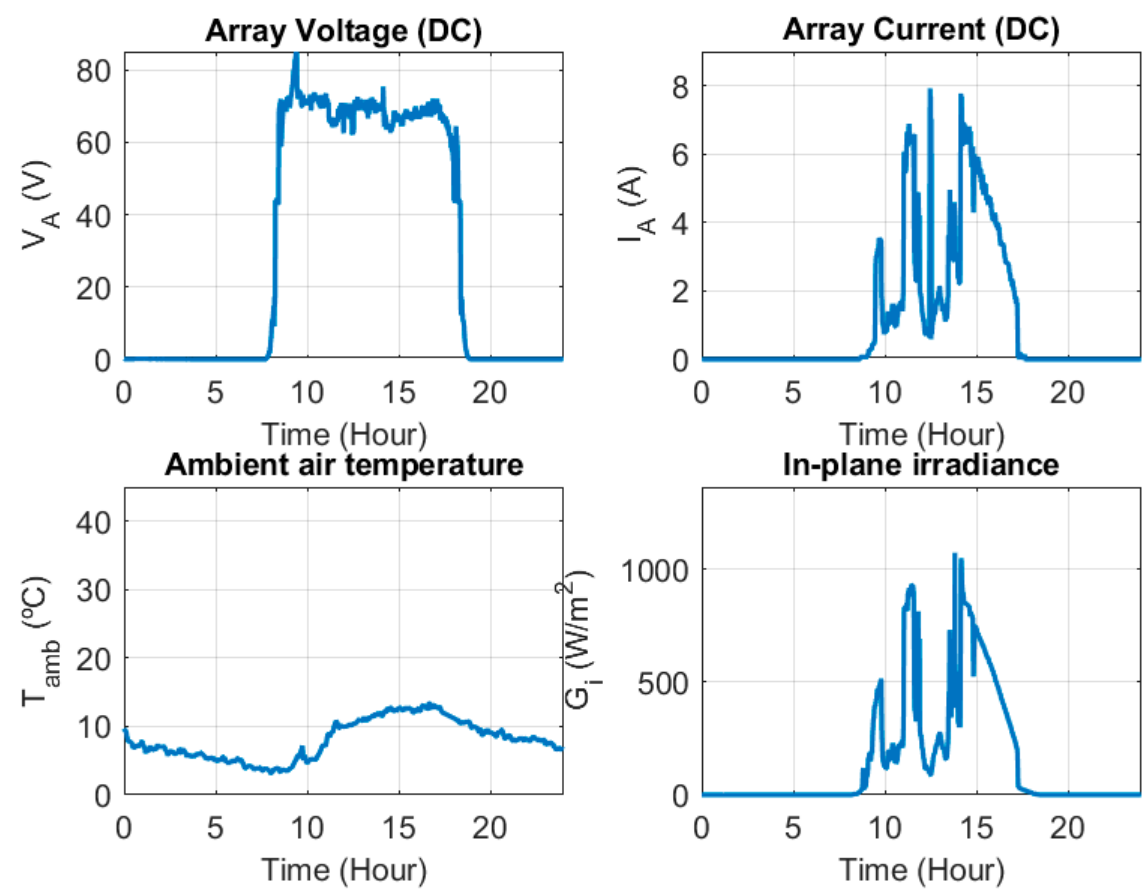

Figure A1. Cont. 
13-Jan-2018
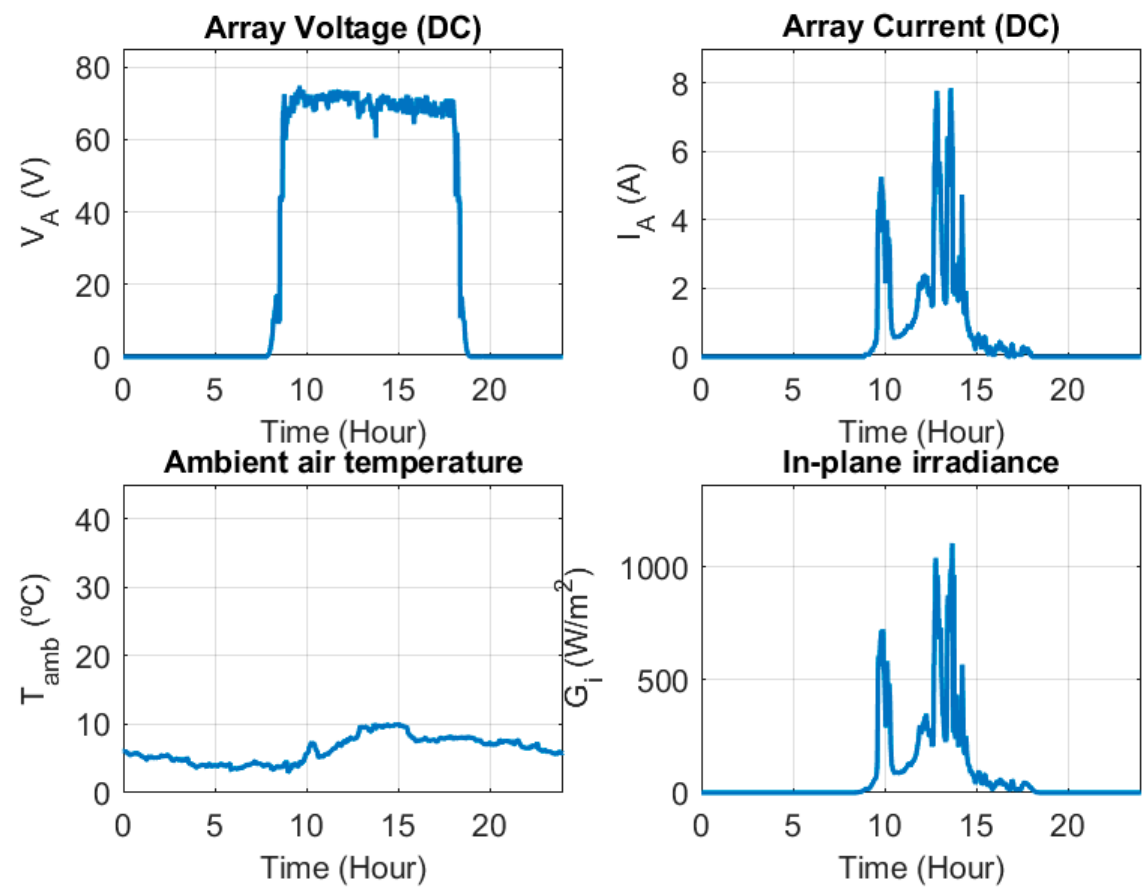

16-Jan-2018
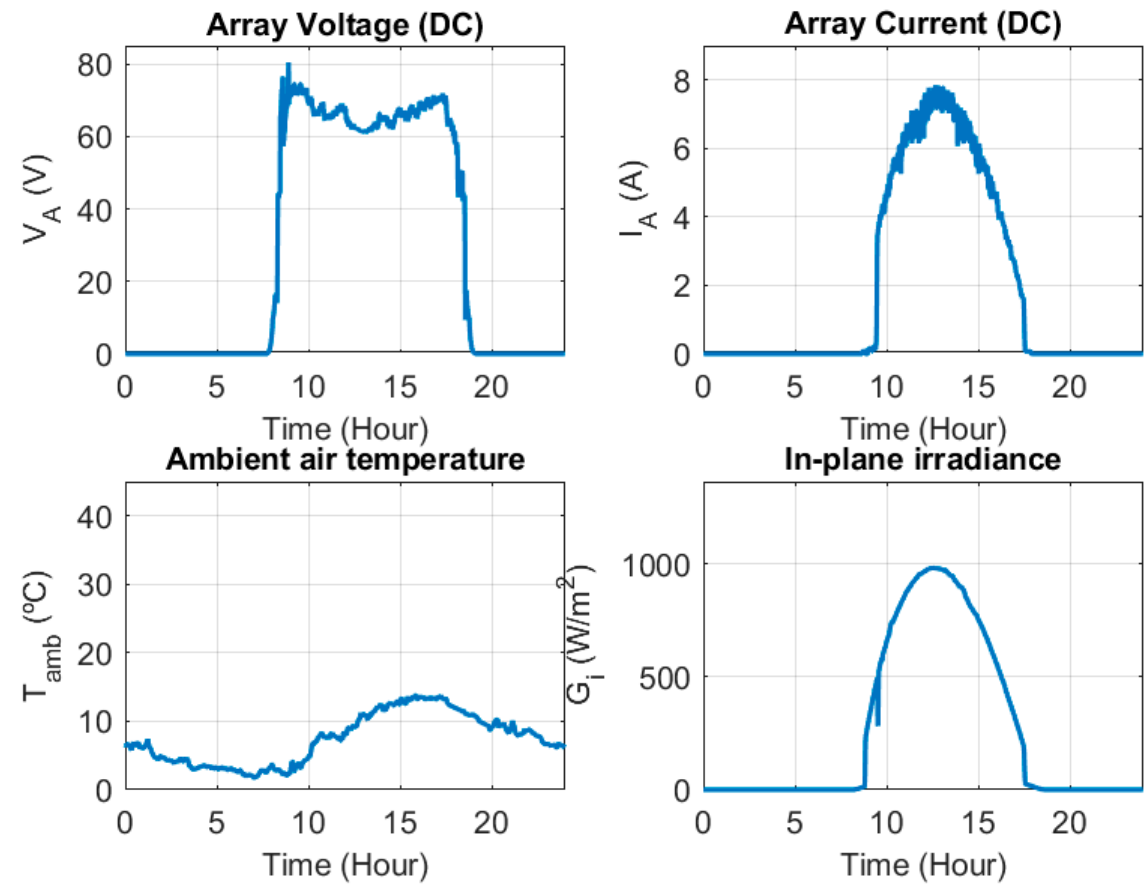

Figure A1. Cont. 
06-Feb-2018
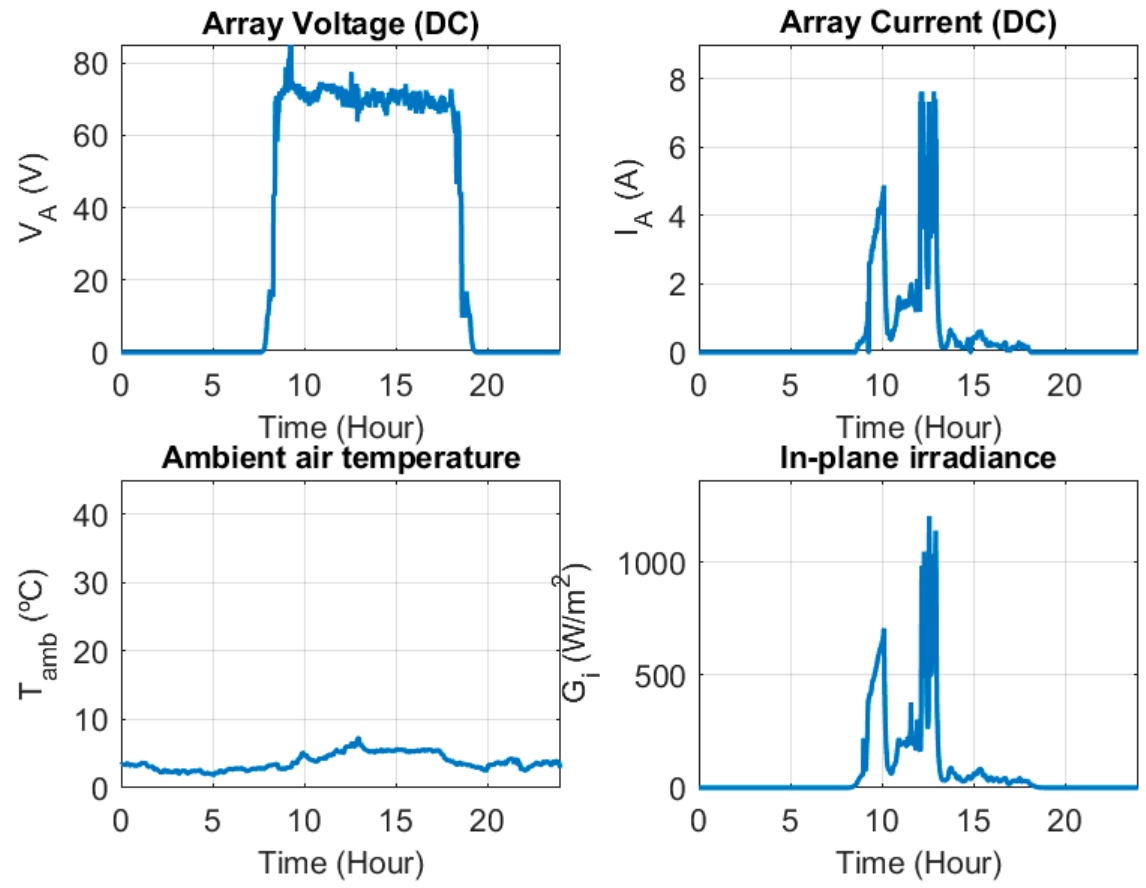

17-Feb-2018
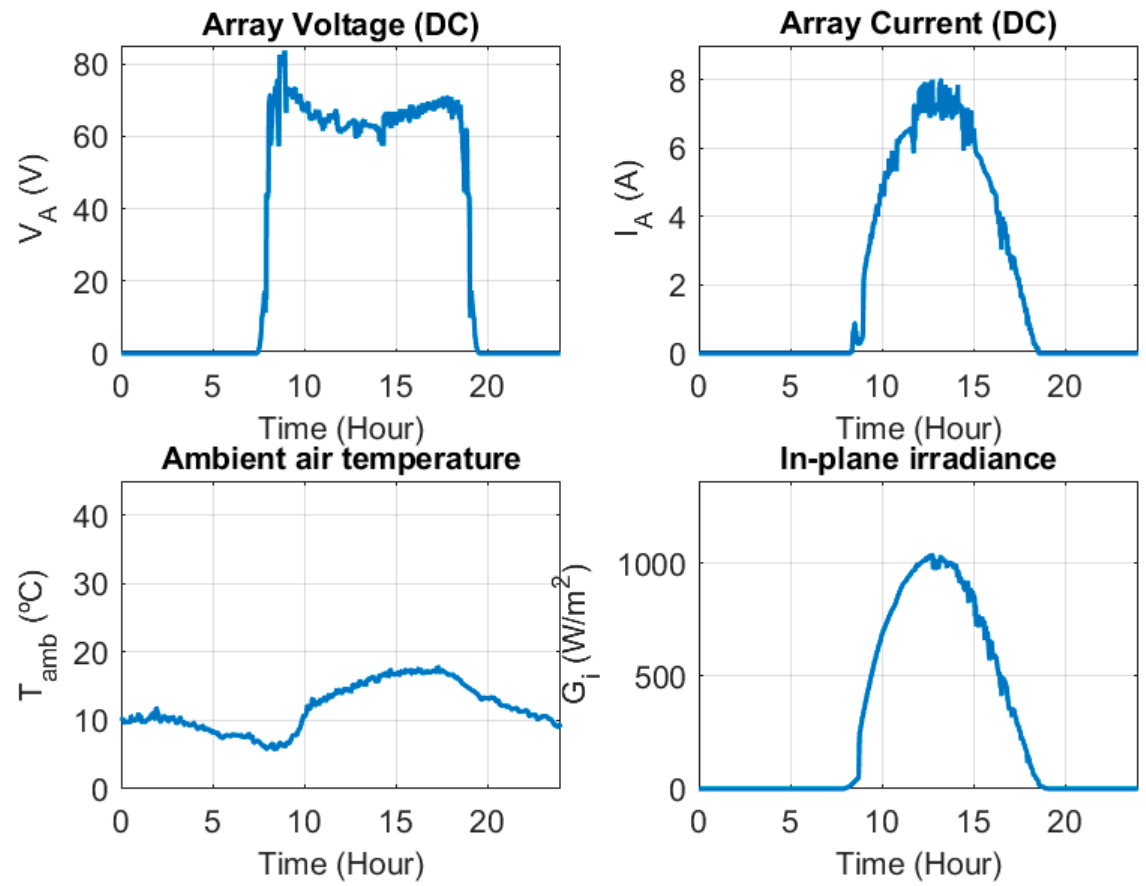

Figure A1. Cont. 
14-Mar-2018
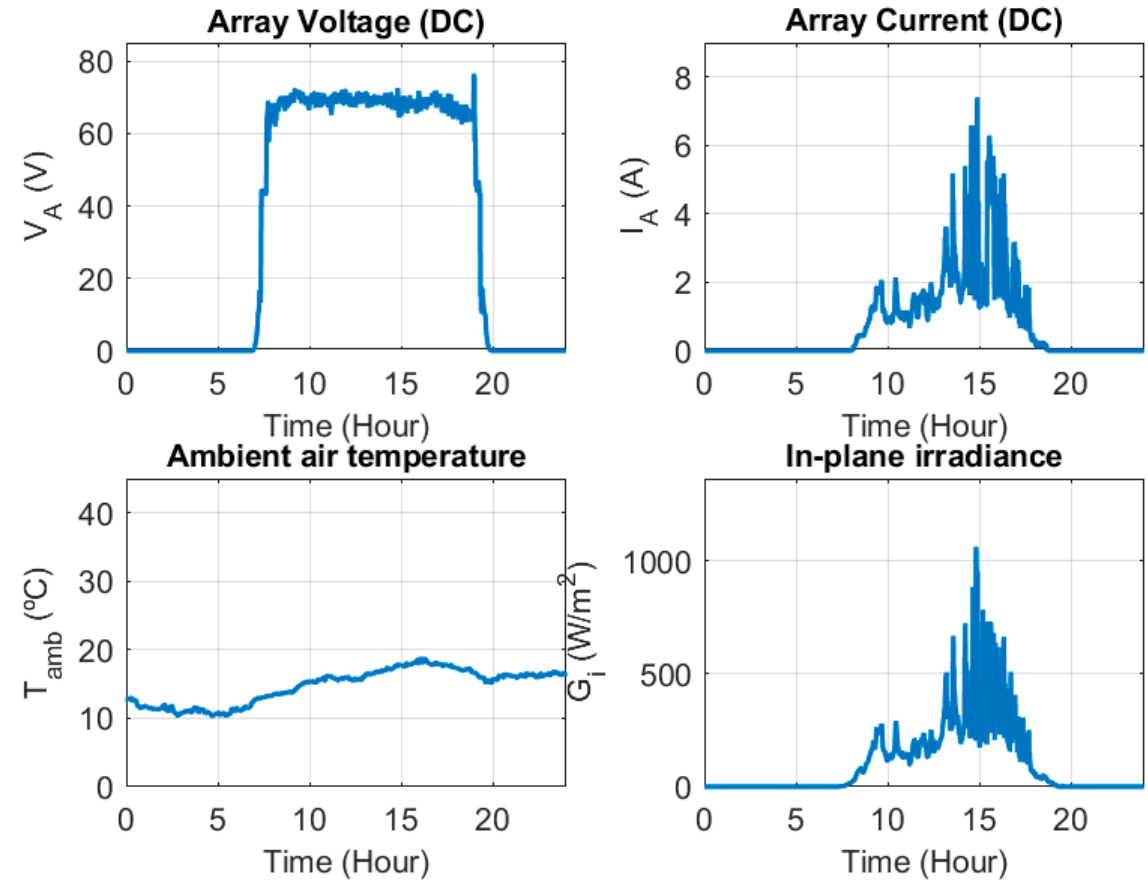

22-Mar-2018
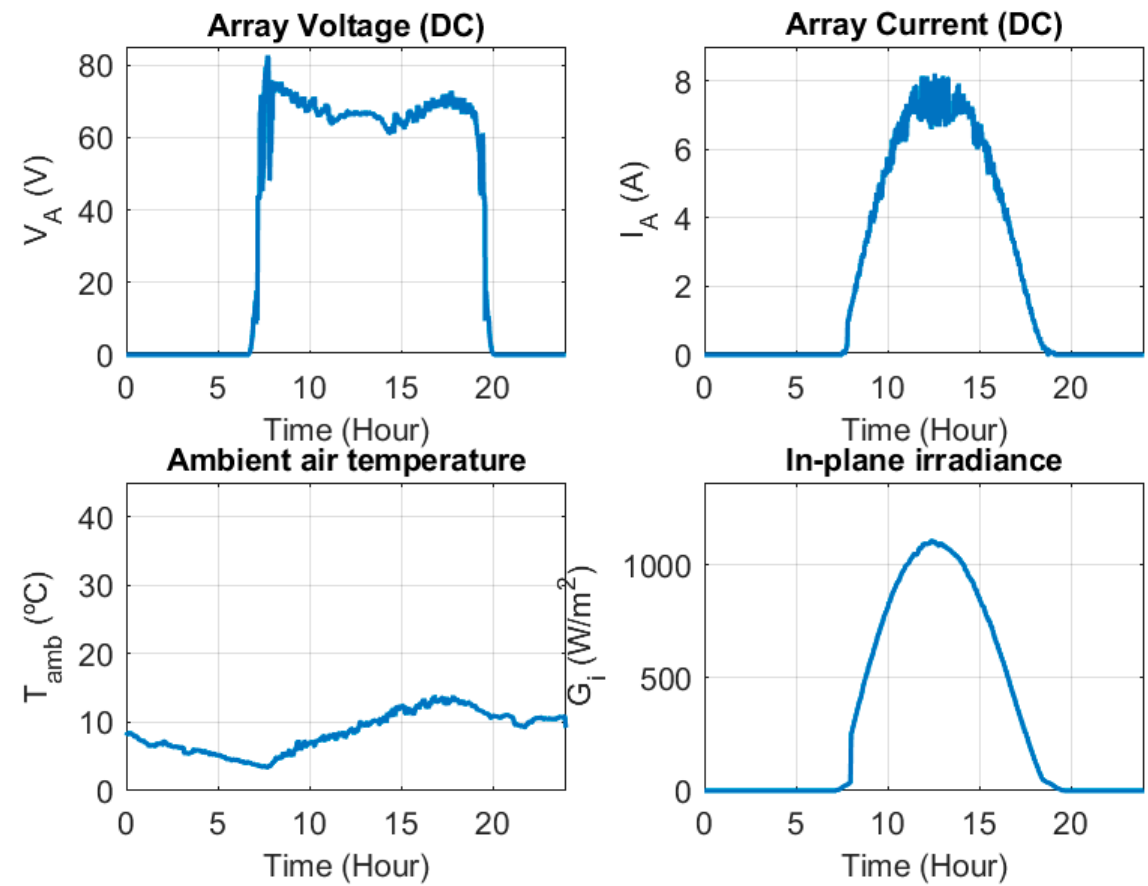

Figure A1. Cont. 
13-Apr-2018
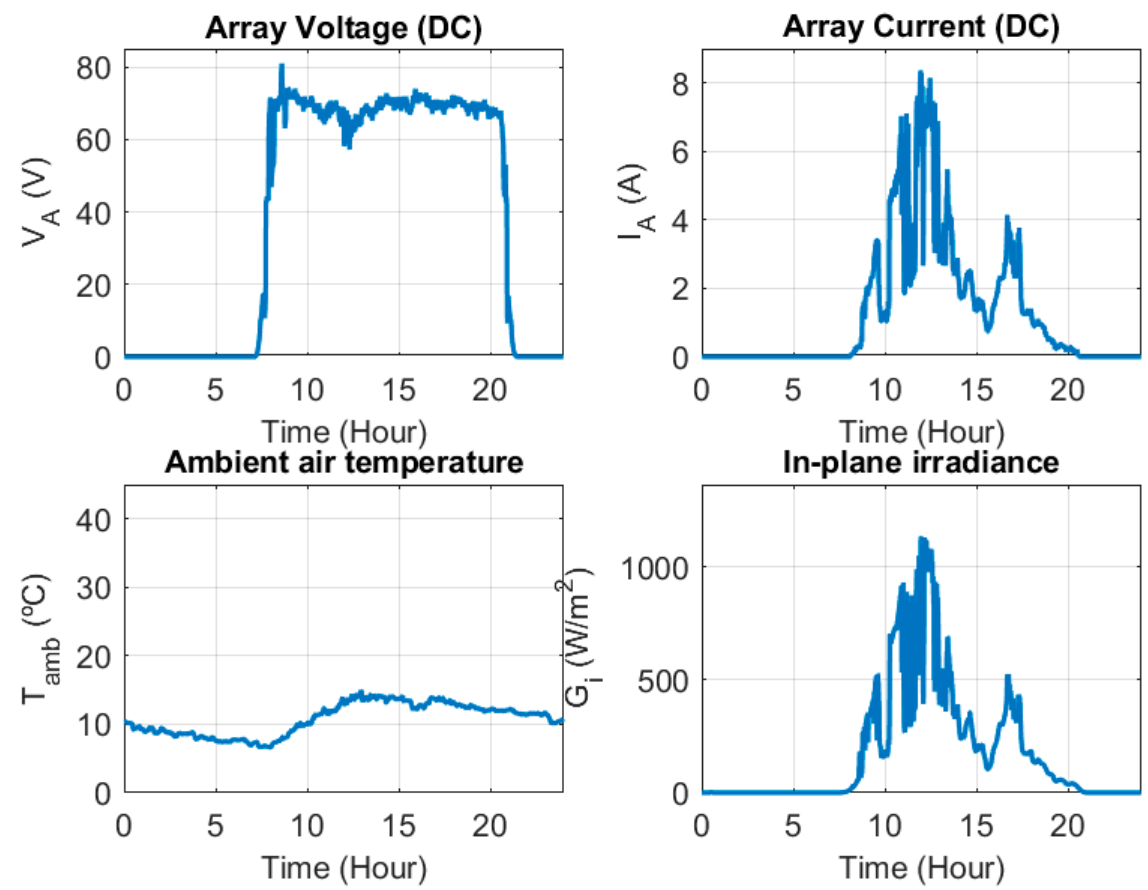

17-Apr-2018
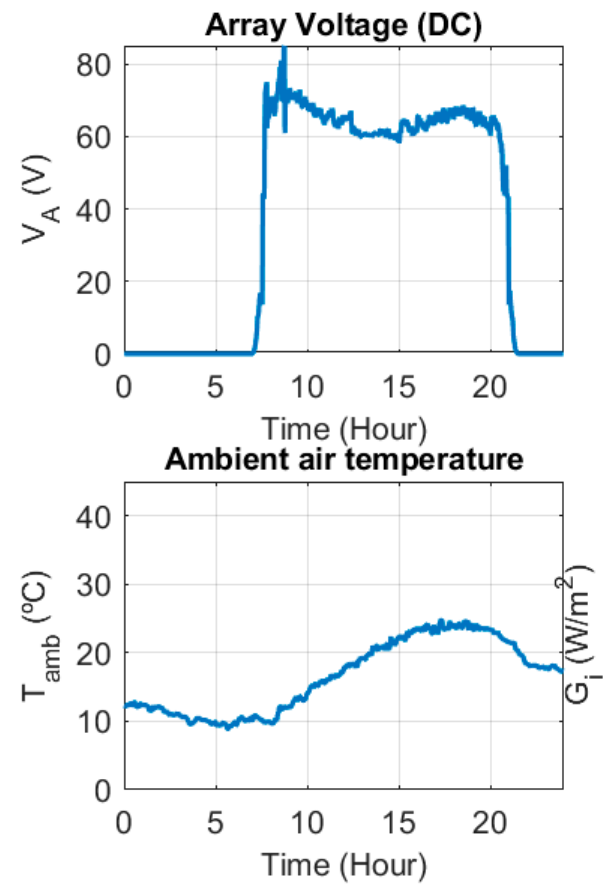

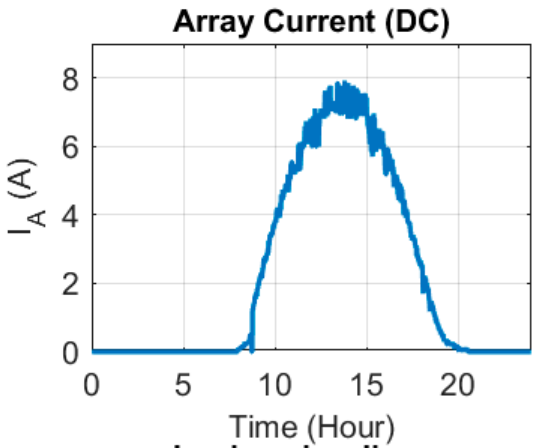

In-plane irradiance

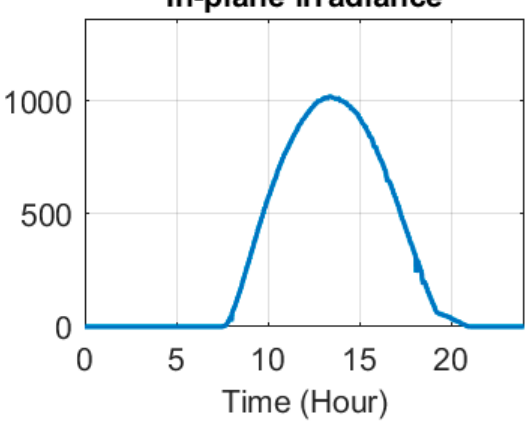

Figure A1. Cont. 
17-May-2018
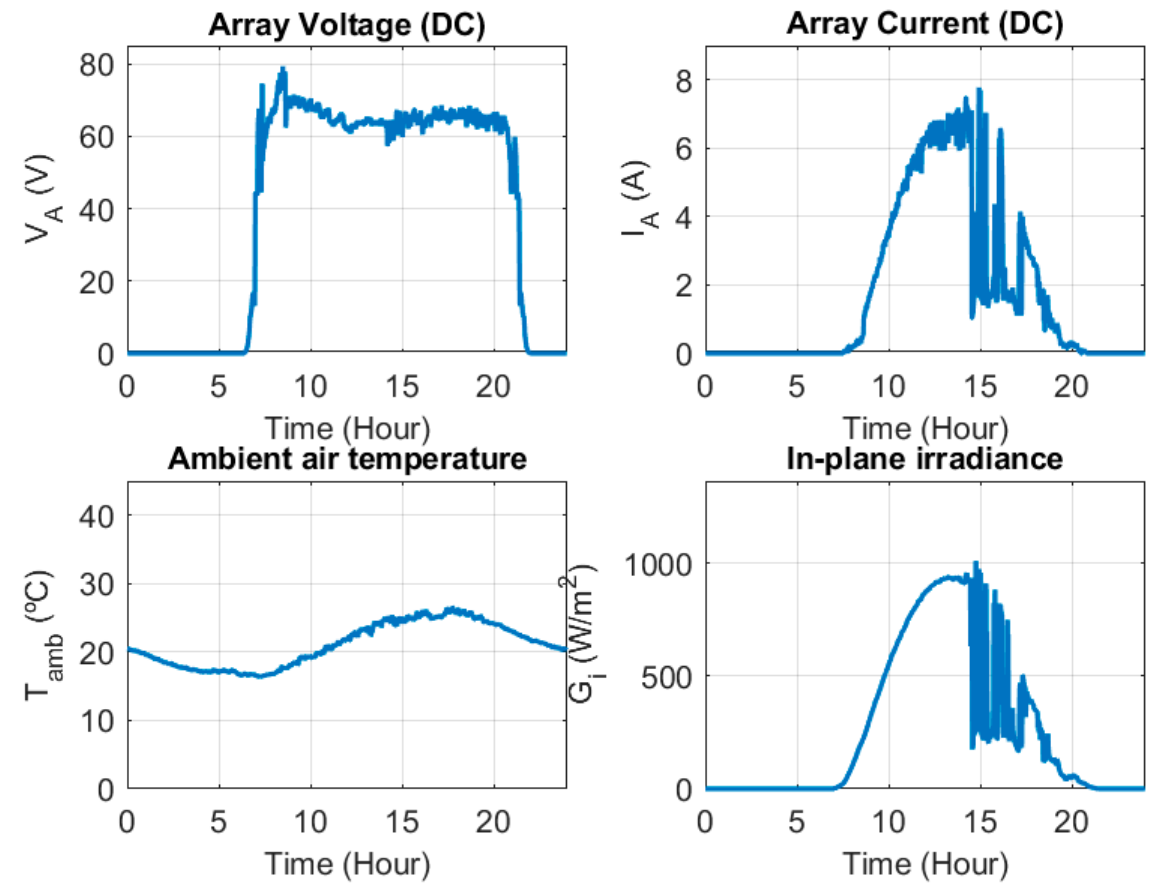

23-May-2018
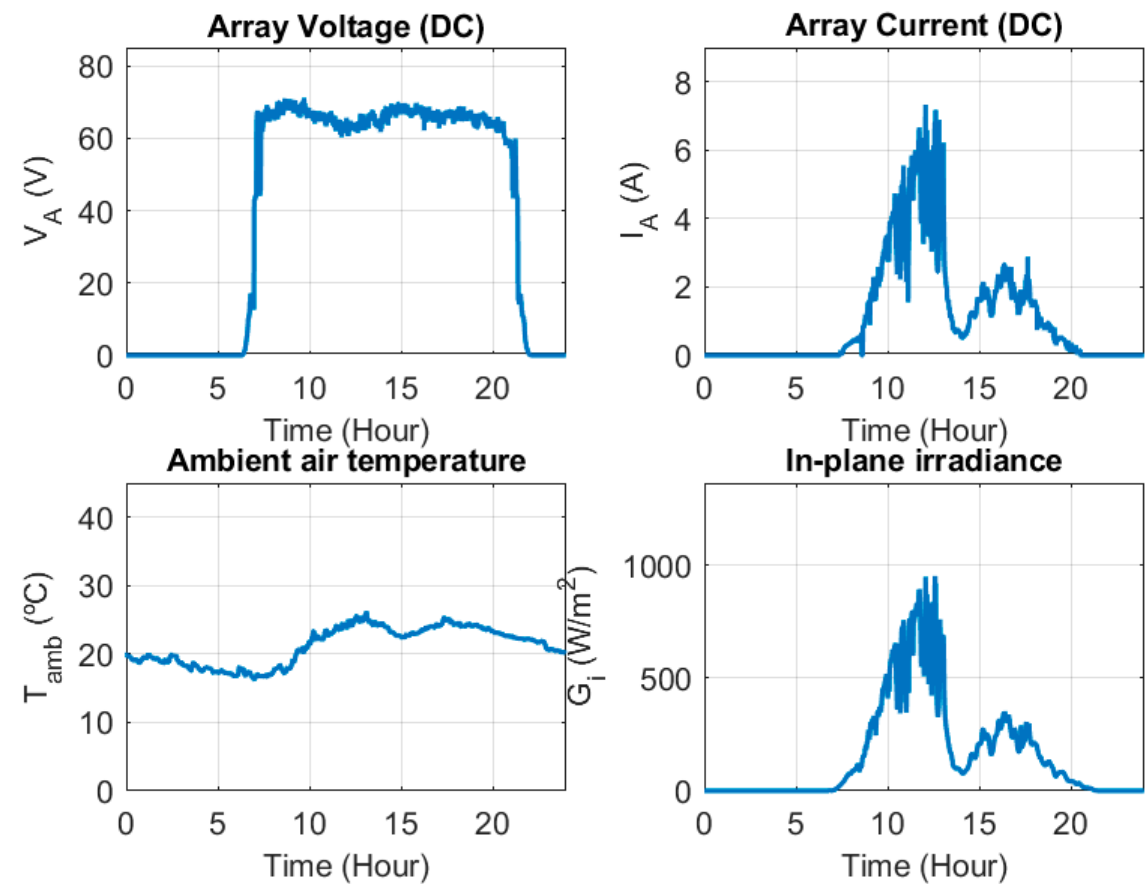

Figure A1. Daily monitored data $\left(\mathrm{V}_{\mathrm{A}}, \mathrm{I}_{\mathrm{A}}, \mathrm{T}_{\mathrm{amb}}\right.$ and $\left.\mathrm{G}_{\mathrm{i}}\right)$ for a cloudy and a sunny day for each month from June 2017 to May 2018.

\section{Appendix B}

Appendix $B$ shows daily monthly average values of $V_{A}, I_{A}, T_{a m b}$ and $G_{i}$ from June 2017 to May 2018. 
June-2017
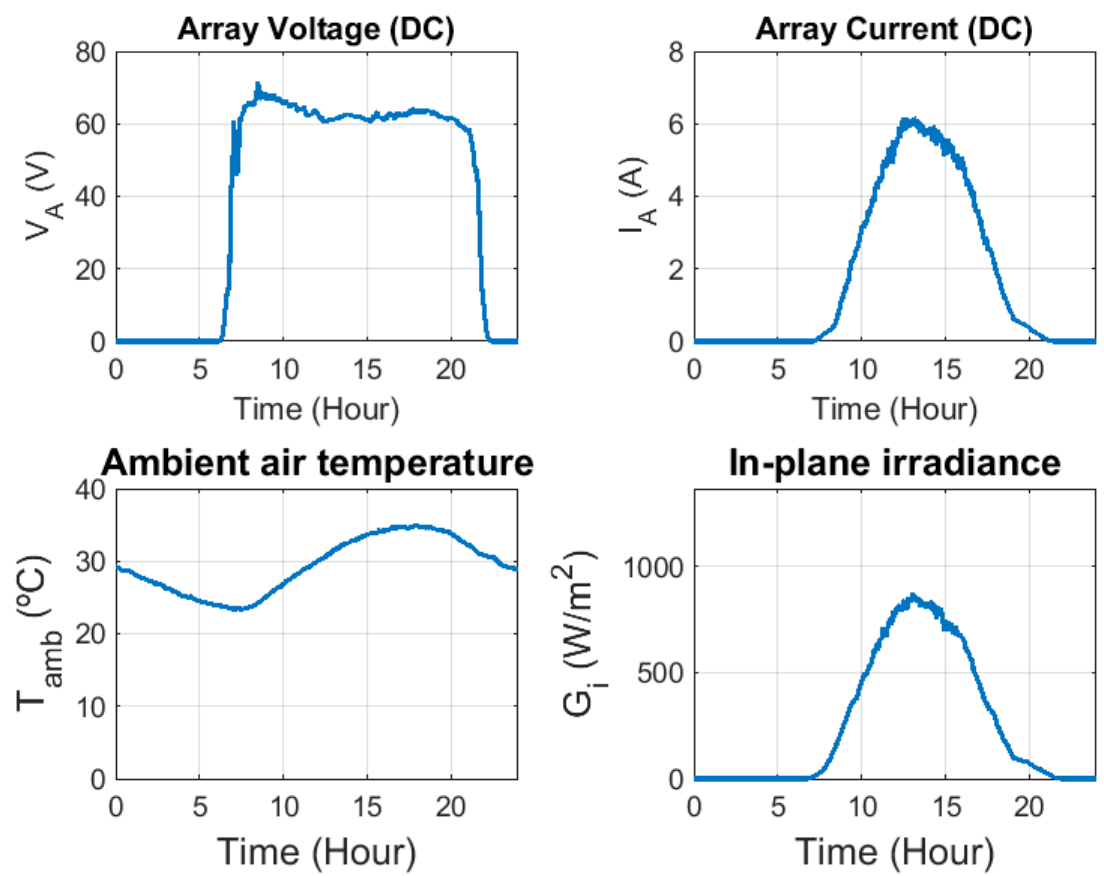

July-2017
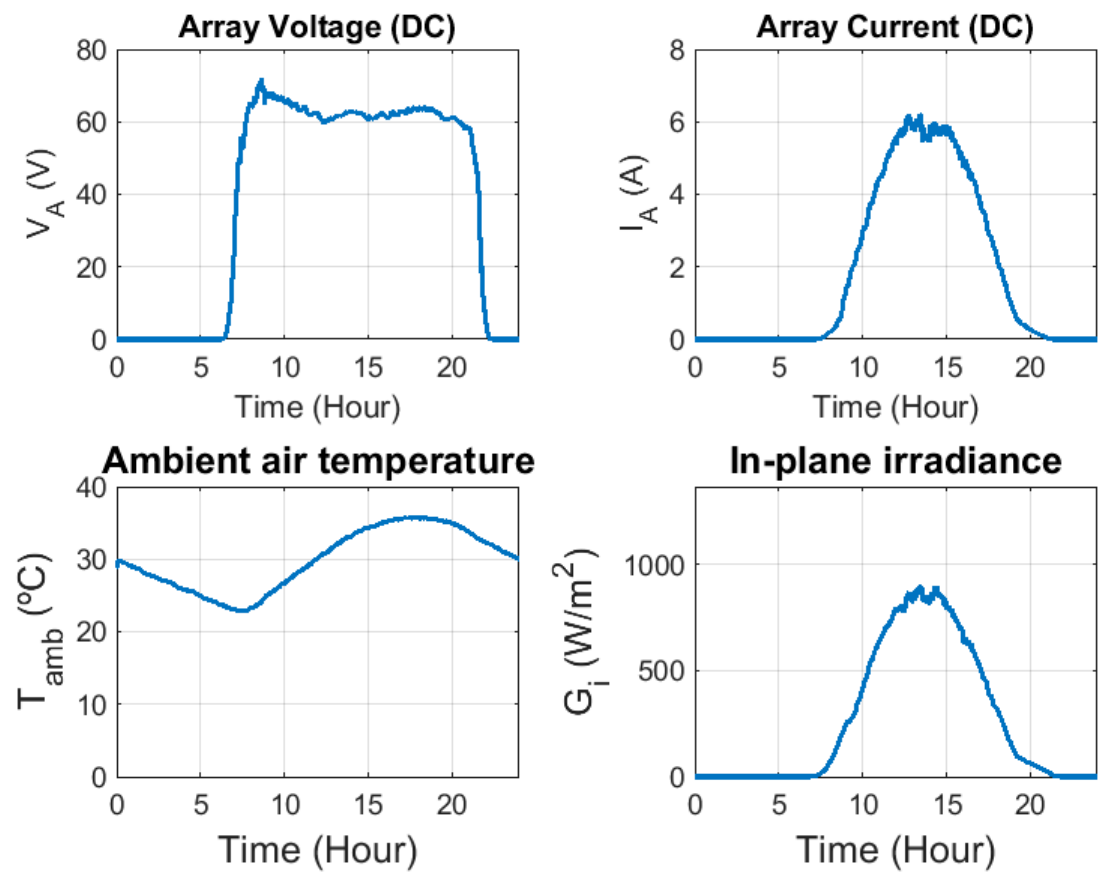

Figure A2. Cont. 
August-2017
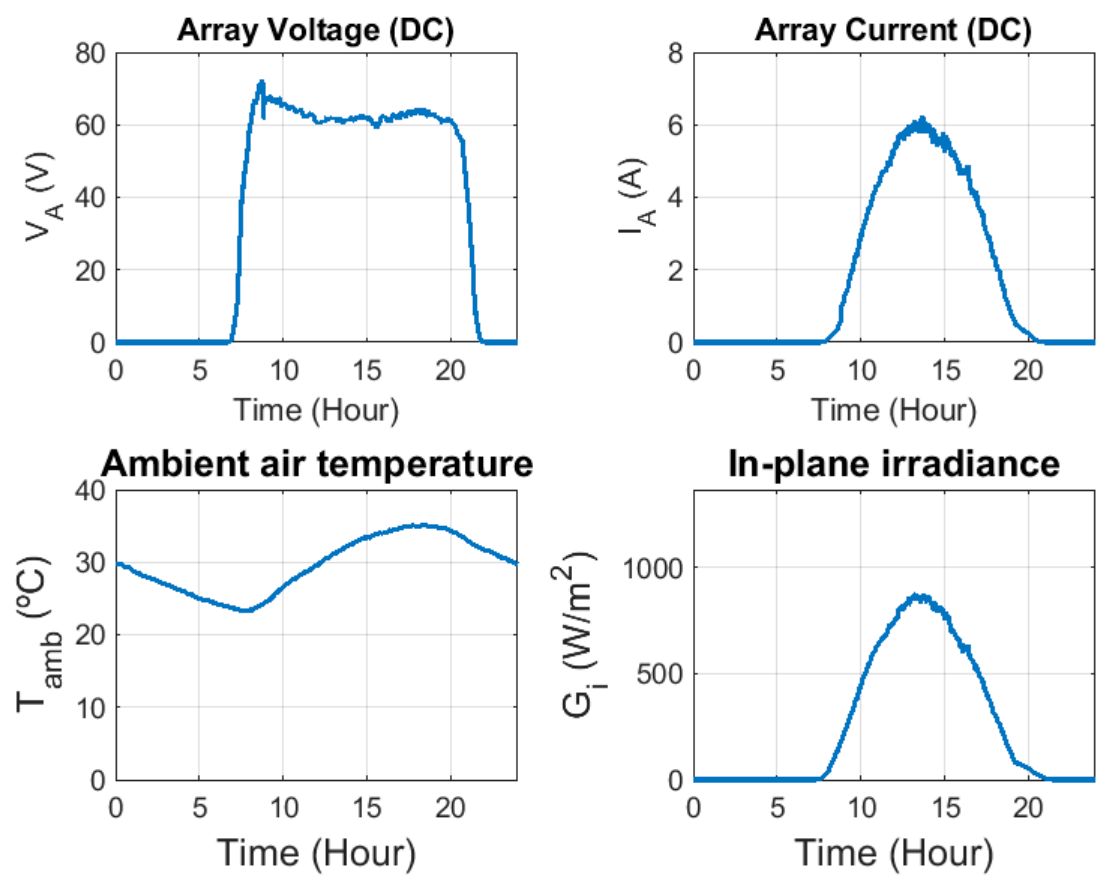

September-2017
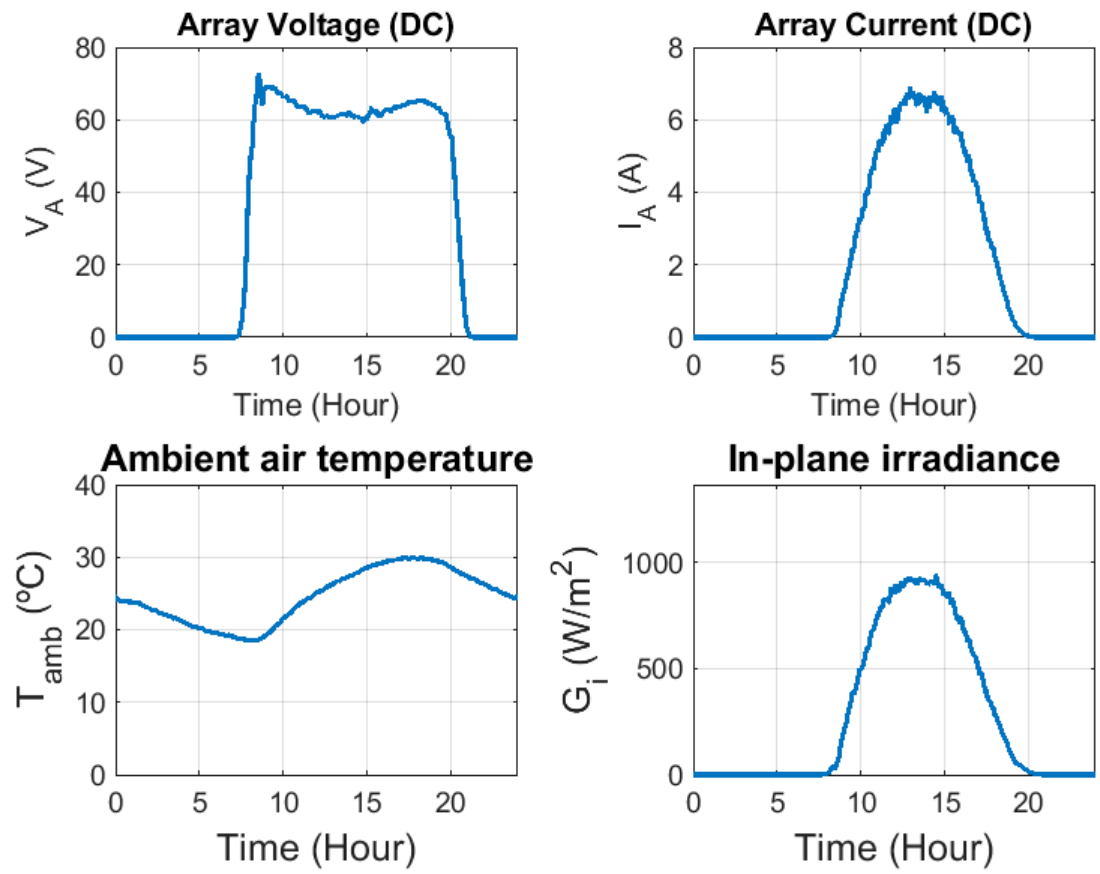

Figure A2. Cont. 
October-2017
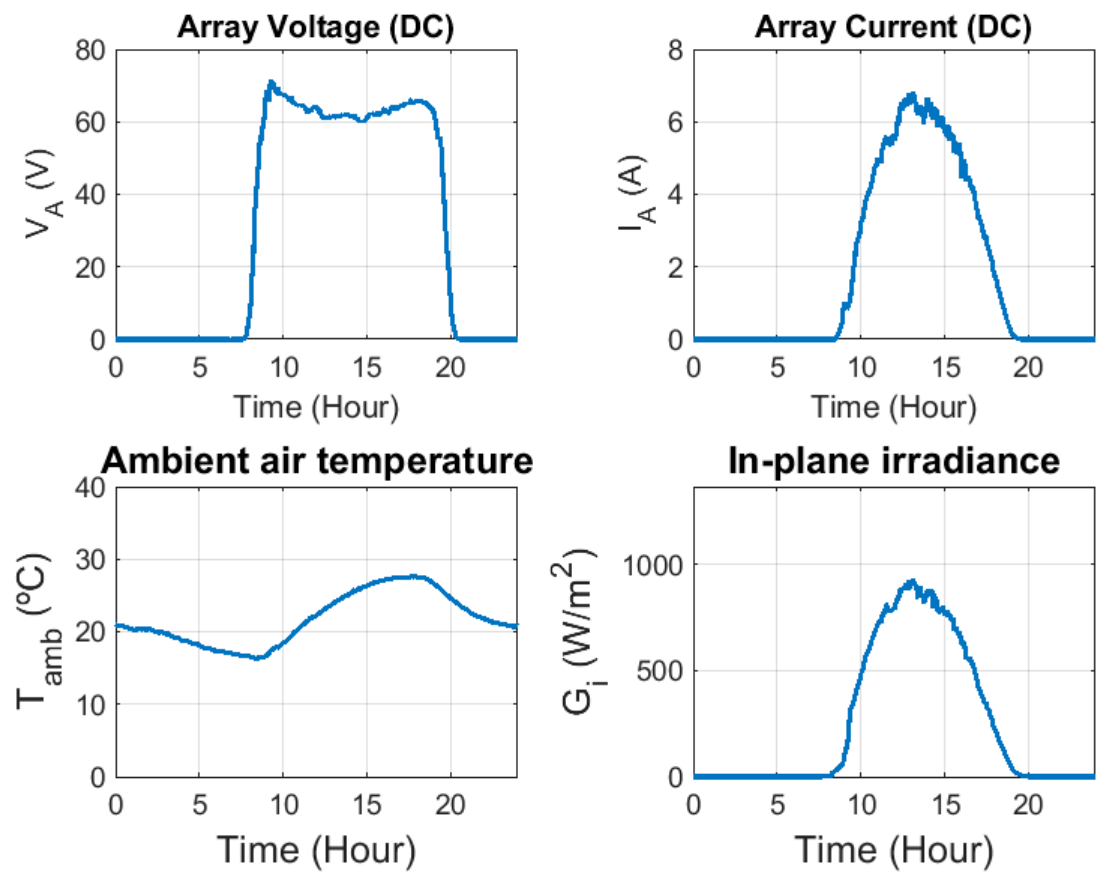

November-2017
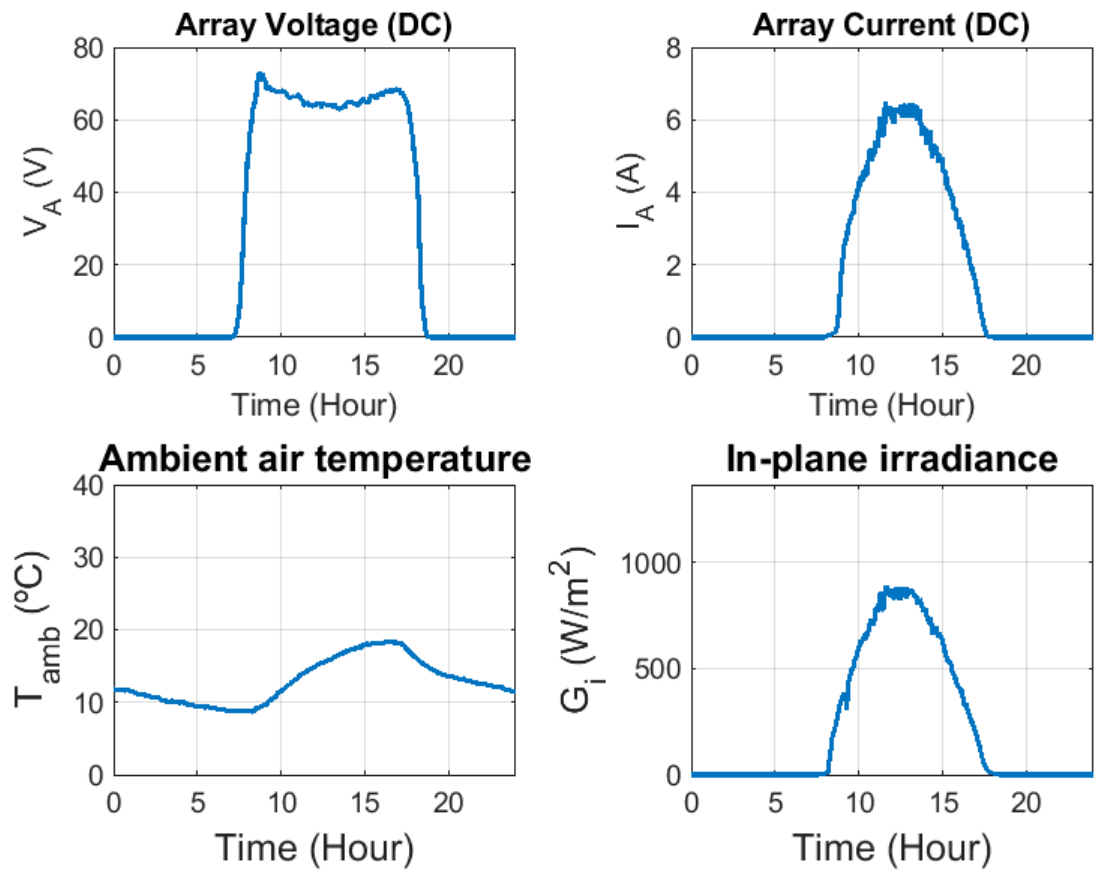

Figure A2. Cont. 
December-2017
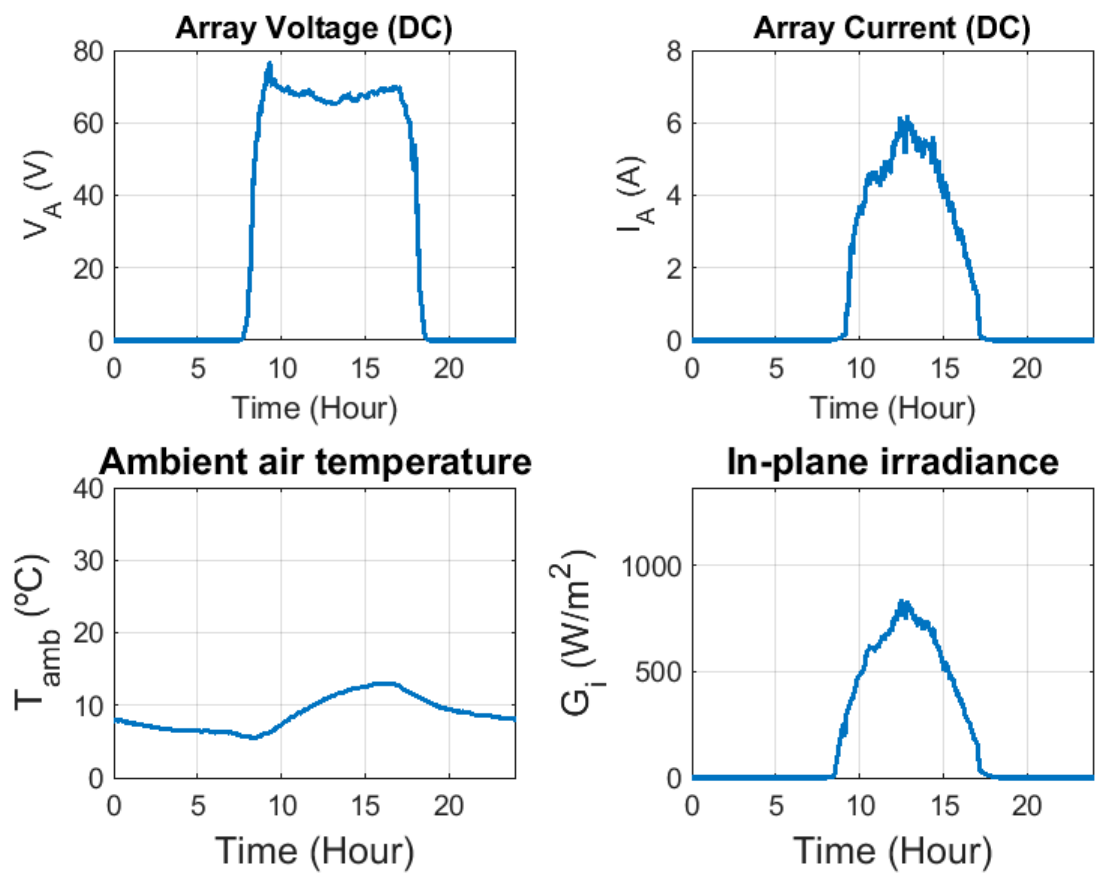

January-2018
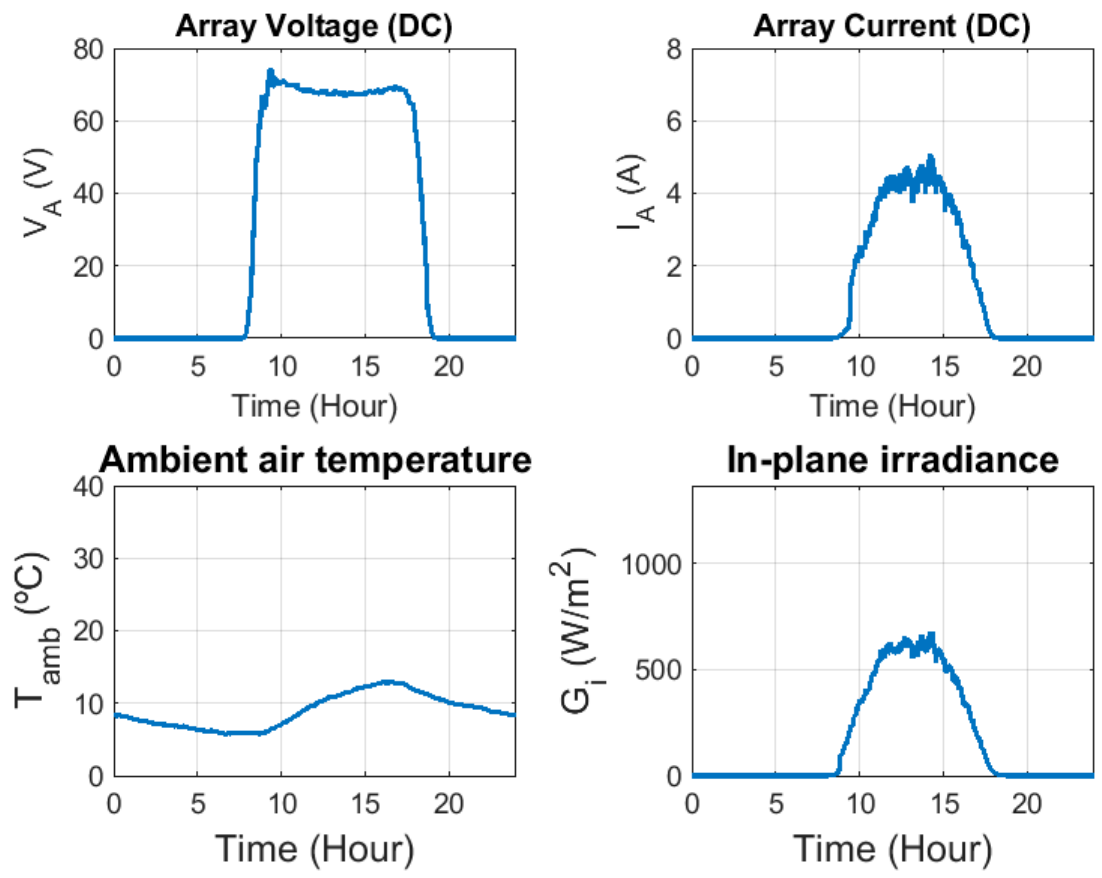

Figure A2. Cont. 
February-2018
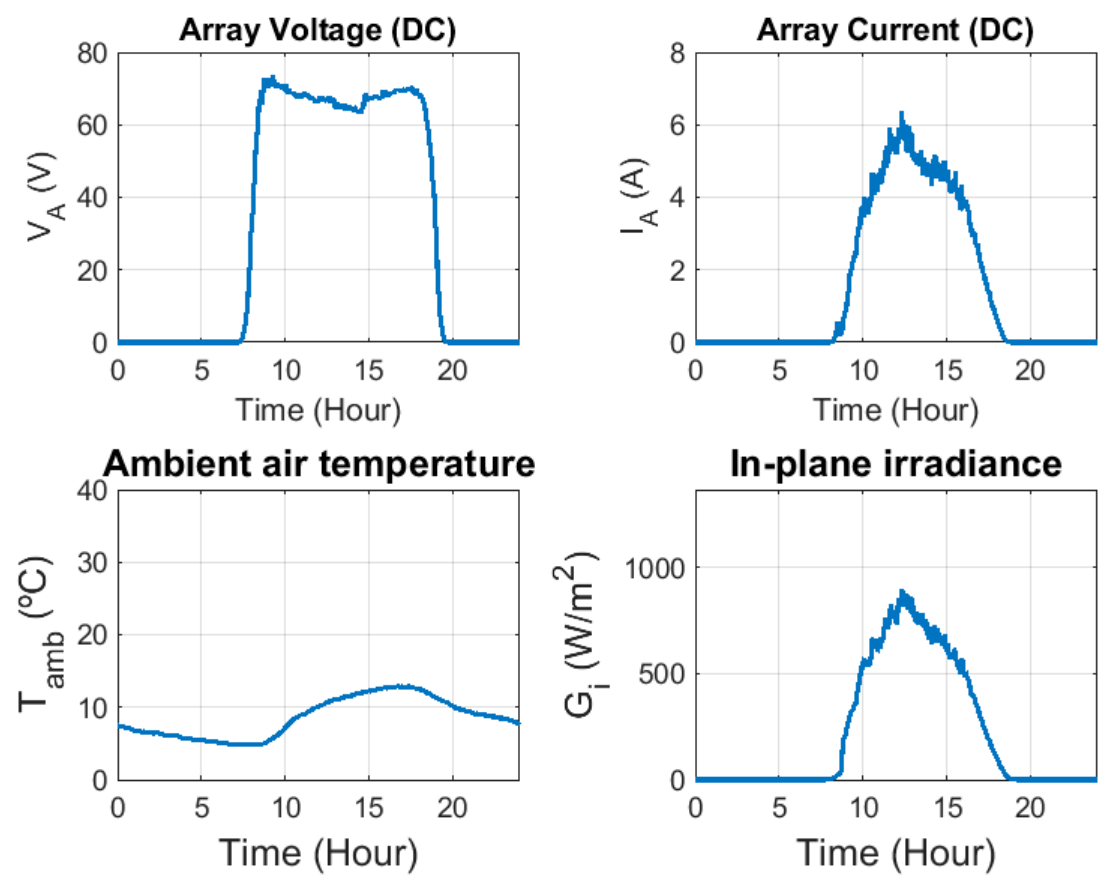

March-2018
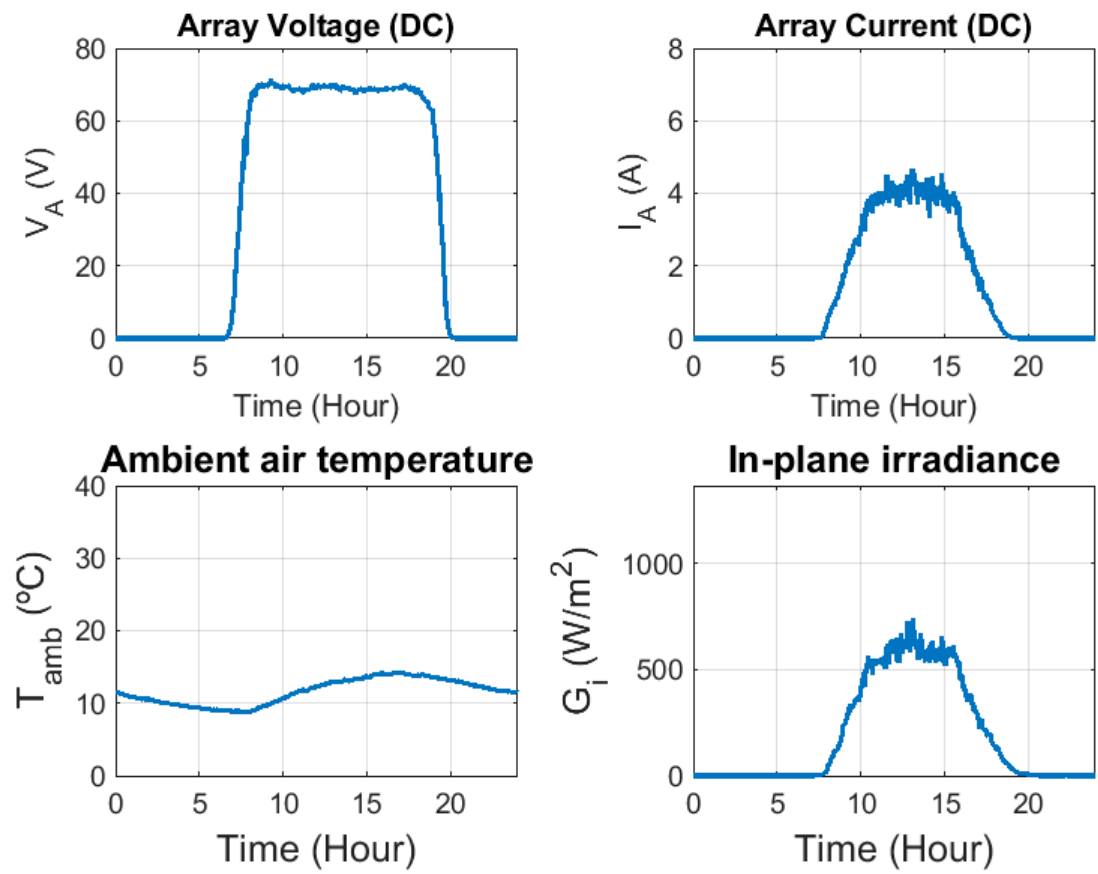

Figure A2. Cont. 
April-2018
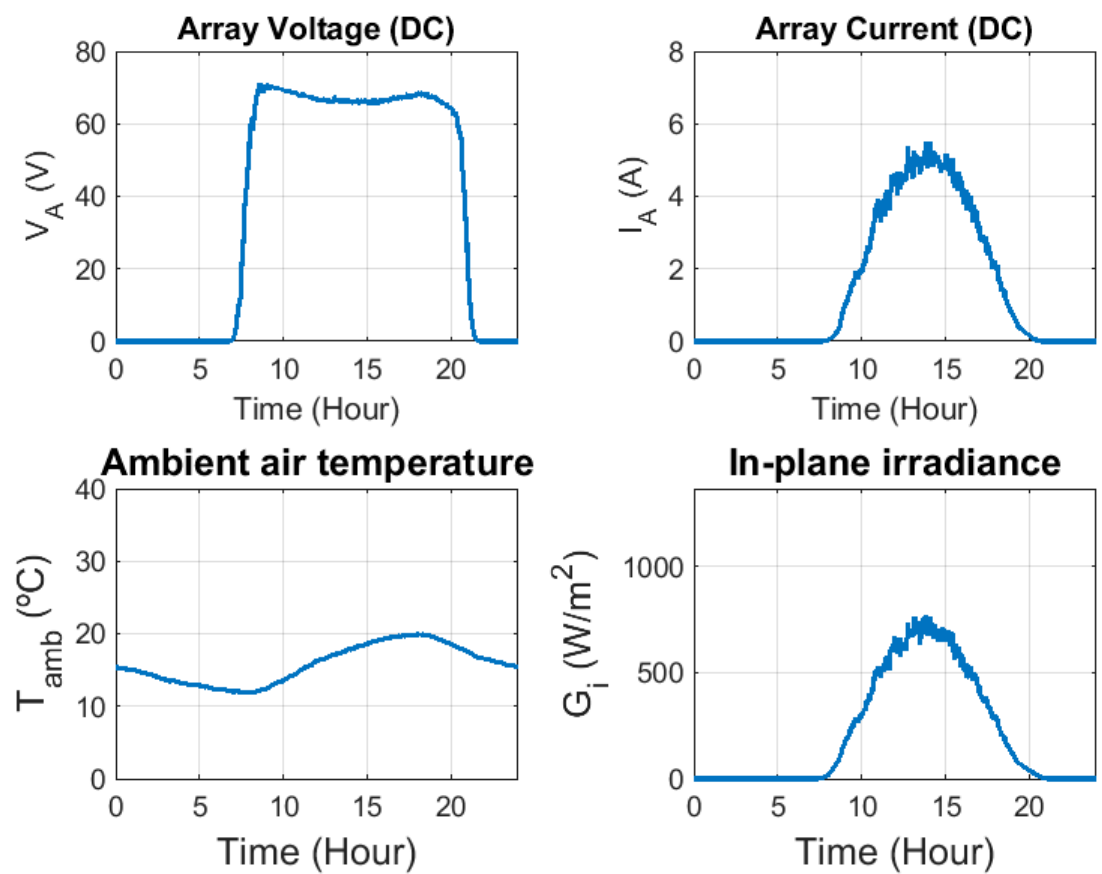

May-2018
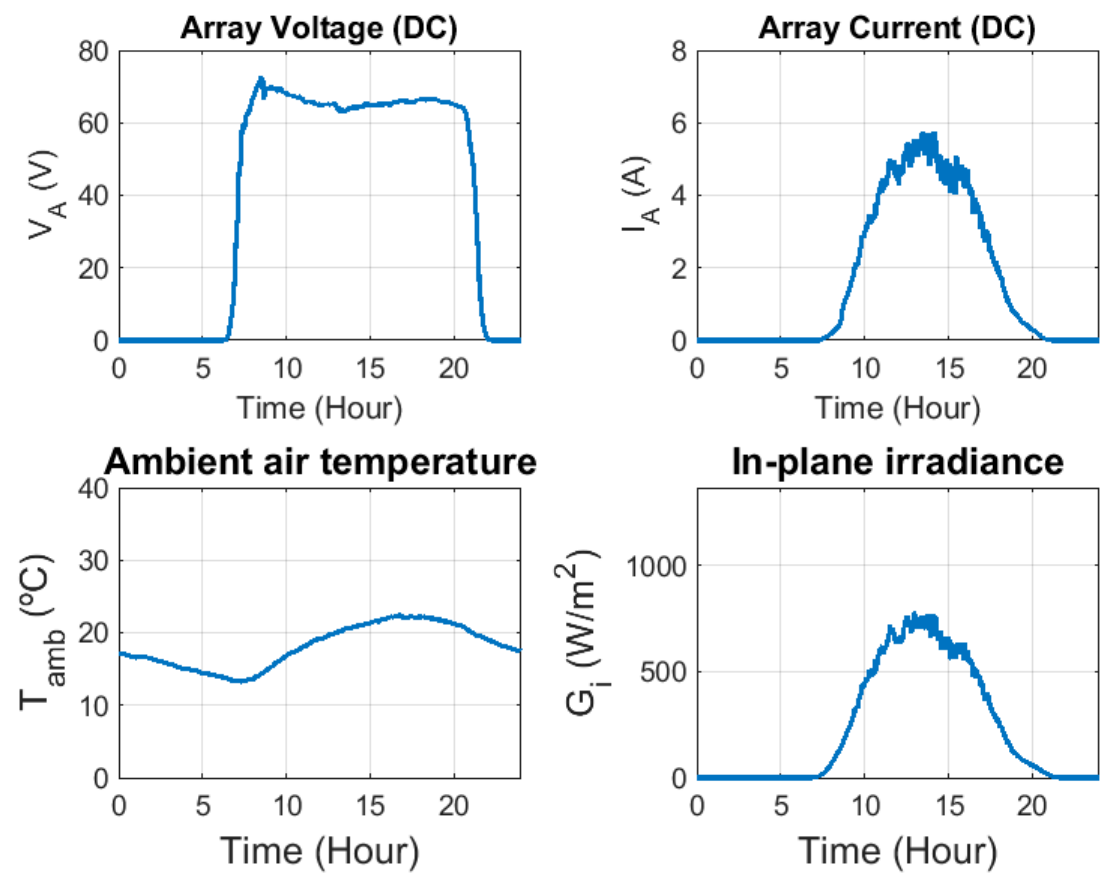

Figure A2. Daily monthly average values of $\mathrm{V}_{\mathrm{A}}, \mathrm{I}_{\mathrm{A}}, \mathrm{T}_{\mathrm{amb}}$ and $\mathrm{G}_{\mathrm{i}}$ from June 2017 to May 2018.

\section{References}

1. REN21. Renewables 2018 Global Status Report. A Comprehensive Annual Overview of the State of Renewable Energy; REN21: Paris, France, 2018.

2. International Renewable Energy Agency (IRENA). REthinking Energy 2017: Accelerating the Global Energy Transformation; IRENA: Abu Dhabi, UAE, 2017; ISBN 9789295111059. 
3. Central Intelligence Agency (CIA). The World Factbook 2019. Available online: https://www.cia.gov/library/ publications/the-world-factbook/geos/xx.html (accessed on 2 October 2019).

4. International Energy Acency. Trends 2018 in Photovoltaic Applications 23. Report IEA PVPS T1-34:2018; International Energy Acency: Paris, France, 2018; pp. 73-91.

5. Kabalci, E. A smart monitoring infrastructure design for distributed renewable energy systems. Energy Convers. Manag. 2015, 90, 336-346. [CrossRef]

6. Olivares, D.E.; Mehrizi-Sani, A.; Etemadi, A.H.; Cañizares, C.A.; Iravani, R.; Kazerani, M.; Hajimiragha, A.H.; Gomis-Bellmunt, O.; Saeedifard, M.; Palma-Behnke, R.; et al. Trends in microgrid control. IEEE Trans. Smart Grid 2014, 5, 1905-1919. [CrossRef]

7. Haegermark, M.; Kovacs, P.; Dalenbäck, J.O. Economic feasibility of solar photovoltaic rooftop systems in a complex setting: A Swedish case study. Energy 2017, 127, 18-29. [CrossRef]

8. Rahbari, O.; Vafaeipour, M.; Omar, N.; Rosen, M.A.; Hegazy, O.; Timmermans, J.M.; Heibati, S.; Bossche, P. Van Den An optimal versatile control approach for plug-in electric vehicles to integrate renewable energy sources and smart grids. Energy 2017, 134, 1053-1067. [CrossRef]

9. Jiménez-Torres, M.; Rus-Casas, C.; Lemus-Zúñiga, L.G.; Hontoria, L. The importance of accurate solar data for designing solar photovoltaic systems-Case studies in Spain. Sustainability 2017, 9, 247. [CrossRef]

10. Rodrigo, P.; Rus, C.; Almonacid, F.; Pérez-Higueras, P.J.; Almonacid, G. A new method for estimating angular, spectral and low irradiance losses in photovoltaic systems using an artificial neural network model in combination with the Osterwald model. Sol. Energy Mater. Sol. Cells 2012, 96, 186-194. [CrossRef]

11. Rus-Casas, C.; Hontoria, L.; Fernández-Carrasco, J.I.; Jiménez-Castillo, G.; Muñoz-Rodríguez, F.J. Development of a Utility Model for the Measurement of Global Radiation in Photovoltaic Applications in the Internet of Things (IoT). Electronics 2019, 8, 304.

12. Hontoria, L.; Rus-Casas, C.; Aguilar, J.D.; Hernandez, J.C. An Improved Method for Obtaining Solar Irradiation Data at Temporal High-Resolution. Sustainability 2019, 11, 5233. [CrossRef]

13. International Energy Agency. Guidelines for Monitoring Stand-Alone Photovoltaic Power Systems-Methodology and Equipment; International Energy Agency: Paris, France, 2003.

14. Ducange, P.; Fazzolari, M.; Lazzerini, B.; Marcelloni, F. An intelligent system for detecting faults in photovoltaic fields. In Proceedings of the International Conference on Intelligent Systems Design and Applications, ISDA, Córdoba, Spain, 22-24 November 2011; pp. 1341-1346.

15. Nofuentes, G.; Aguilera, J.; Rus, C.; Santiago, S. A short assessment on the profitability of PV grid-connected systems using classical investment project analysis. In Proceedings of the 3rd World Conference on Photovoltaic Energy Conversion, Osaka, Japan, 11-18 May 2003.

16. Shrihariprasath, B.; Rathinasabapathy, V. A smart IoT system for monitoring solar PV power conditioning unit. In Proceedings of the IEEE WCTFTR 2016-World Conference on Futuristic Trends in Research and Innovation for Social Welfare, Coimatore, India, 29 February-1 March 2016.

17. Urmee, T.; Harries, D.; Schlapfer, A. Issues related to rural electrification using renewable energy in developing countries of Asia and Pacific. Renew. Energy 2009, 34, 354-357. [CrossRef]

18. Fuentes, M.; Vivar, M.; Burgos, J.M.; Aguilera, J.; Vacas, J.A. Design of an accurate, low-cost autonomous data logger for PV system monitoring using Arduino ${ }^{\mathrm{TM}}$ that complies with IEC standards. Sol. Energy Mater. Sol. Cells 2014, 130, 529-543. [CrossRef]

19. Fanourakis, S.; Wang, K.; McCarthy, P.; Jiao, L. Low-cost data acquisition systems for photovoltaic system monitoring and usage statistics. IOP Conf. Ser. Earth Environ. Sci. 2017, 93, 12048. [CrossRef]

20. El Hammoumi, A.; Motahhir, S.; Chalh, A.; El Ghzizal, A.; Derouich, A. Low-cost virtual instrumentation of PV panel characteristics using Excel and Arduino in comparison with traditional instrumentation. Renew. Wind. Water Sol. 2018, 5, 3. [CrossRef]

21. Mahjoubi, A.; Mechlouch, R.F.; Brahim, A. Ben A low cost wireless data acquisition system for a remote photovoltaic (PV) water pumping system. Energies 2011, 4, 68-89. [CrossRef]

22. Gubbi, J.; Buyya, R.; Marusic, S.; Palaniswami, M. Internet of Things (IoT): A vision, architectural elements, and future directions. Futur. Gener. Comput. Syst. 2013, 29, 1645-1660. [CrossRef]

23. Ray, P.P. A survey of IoT cloud platforms. Future Comput. Inform. J. 2016, 1, 35-46. [CrossRef]

24. Mineraud, J.; Mazhelis, O.; Su, X.; Tarkoma, S. A gap analysis of Internet-of-Things platforms. Comput. Commun. 2016, 89-90, 5-16. [CrossRef] 
25. Paredes-Parra, J.M.; García-Sánchez, A.J.; Mateo-Aroca, A.; Molina-García, Á. An alternative internet-of-things solution based on LOra for PV power plants: Data monitoring and management. Energies 2019, 12, 881. [CrossRef]

26. Kim, J.; Byun, J.; Jeong, D.; Choi, M.I.; Kang, B.; Park, S. An IoT-Based Home Energy Management System over Dynamic Home Area Networks. Int. J. Distrib. Sens. Netw. 2015, 11, 1-15. [CrossRef]

27. Torres, M.; Muñoz, F.J.; Muñoz, J.V.; Rus, C.; Muñoz, F.J.; Muñoz, J.V.; Rus, C.; Muñoz, F.J.; Muñoz, J.V.; Rus, C. Online Monitoring System for Stand-Alone Photovoltaic Applications-Analysis of System Performance From Monitored Data. J. Sol. Energy Eng. 2012, 134, 034502. [CrossRef]

28. Jiménez-Castillo, G.; Muñoz-Rodríguez, F.J.; Rus-Casas, C.; Gómez-Vidal, P. Improvements in Performance Analysis of Photovoltaic Systems: Array Power Monitoring in Pulse Width Modulation Charge Controllers. Sensors 2019, 19, 2150. [CrossRef]

29. Jiménez-Castillo, G.; Muñoz-Rodríguez, F.; Rus-Casas, C.; Hernández, J.C.; Tina, G. Monitoring PWM signals in stand-alone photovoltaic systems. Measurement 2019, 134, 412-425. [CrossRef]

30. Kekre, A.; Gawre, S.K. Solar photovoltaic remote monitoring system using IOT. In Proceedings of the International Conference on Recent Innovations in Signal Processing and Embedded Systems (RISE), Bhopal, India, 27-29 October 2018; Institute of Electrical and Electronics Engineers Inc.: Piscataway, NJ, USA, 2018; pp. 619-623.

31. Talavera, D.L.; Muñoz-Rodriguez, F.J.; Jimenez-Castillo, G.; Rus-Casas, C. A new approach to sizing the photovoltaic generator in self-consumption systems based on cost-competitiveness, maximizing direct self-consumption. Renew. Energy 2019, 130, 1021-1035. [CrossRef]

32. Jiménez-Castillo, G.; Muñoz-Rodriguez, F.J.; Rus-Casas, C.; Talavera, D.L. A new approach based on economic profitability to sizing the photovoltaic generator in self-consumption systems without storage. Renew. Energy 2019. [CrossRef]

33. Sanchez-Sutil, F.; Cano-Ortega, A.; Hernandez, J.C.; Rus-Casas, C. Development and Calibration of an Open Source, Low-Cost Power Smart Meter Prototype for PV Household-Prosumers. Electronics 2019, 8, 878. [CrossRef]

34. Jiménez-Castillo, G.; Tina, G.-M.; Muñoz-Rodríguez, F.-J.; Rus-Casas, C. Smart meters for the evaluation of self-consumption in zero energy buildings. In Proceedings of the 2019 10th International Renewable Energy Congress (IREC), Sousse, Tunisia, 26-28 March 2019; pp. 1-6.

35. IEC. IEC TS 61724-3 Edition 1.0 2016-07. Photovoltaic System Performance-Part 3: Energy Evaluation Method Colour, 1st ed.; IEC Publications: Geneva, Switzerland, 2016; ISBN 9782832235317.

36. Belmili, H.; Ait Cheikh, S.M.; Haddadi, M.; Larbes, C. Design and development of a data acquisition system for photovoltaic modules characterization. Renew. Energy 2010, 35, 1484-1492. [CrossRef]

37. Rus-Casas, C.; Hontoria, L.; Muñoz-Rodríguez, F.J.; Fernández-Carrasco, J.I.; Jiménez-Torres, M. Sistema para la monitorización de la radiación solar. Modelo de utilidad U201830617, 6 June 2018.

38. Maxim DS18B20. Available online: http://www.maximintegrated.com (accessed on 15 October 2019).

39. Jankovec, M.; Topič, M. Intercomparison of temperature sensors for outdoor monitoring of photovoltaic modules. J. Sol. Energy Eng. Trans. ASME 2013, 135, 031012. [CrossRef]

40. Barbato, M.; Meneghini, M.; Cester, A.; Mura, G.; Zanoni, E.; Meneghesso, G. Influence of shunt resistance on the performance of an illuminated string of solar cells: Theory, simulation, and experimental analysis. IEEE Trans. Device Mater. Reliab. 2014, 14, 942-950. [CrossRef]

41. Scelba, G.; De Donato, G.; Pulvirenti, M.; Giulii Capponi, F.; Scarcella, G. Hall-Effect Sensor Fault Detection, Identification and Compensation in Brushless DC Drives. IEEE Trans. Ind. Appl. 2015, 52, 1542-1554. [CrossRef]

42. Díaz-Rodríguez, J.L.; Pabón-Fernández, L.D.; Contreras-Peña, J.L. Plataforma de bajo costo para la evaluación de fenómenos electromagnéticos monofásicos de calidad de la energía según el estándar IEEE 1159. DYNA 2015, 82, 119-129.

43. ACS714. Available online: https://www.allegromicro.com/en/Products/Current-Sensor-ICs/Zero-To-FiftyAmp-Integrated-Conductor-Sensor-ICs/ACS714.aspx (accessed on 6 March 2019).

44. RedLion Model IAMA-Universal Signal Conditioning Module. Available online: www.redlion.net (accessed on 5 June 2019).

45. YHDC Split Core Current Transformer. Available online: http://www.mcielectronics.cl/website_MCI/static/ documents/Datasheet_SCT013.pdf (accessed on 5 June 2019). 
46. Devices, A. Single-Phase Multifunction Metering IC with di/dt Sensor Interface ADE7753. Available online: http://www.analog.com (accessed on 5 June 2019).

47. Morales, R.; Badesa, F.J.; García-Aracil, N.; Perez-Vidal, C.; Sabater, J.M. Distributed smart device for monitoring, control and management of electric loads in domotic environments. Sensors 2012, 12, 5212-5224. [CrossRef]

48. Gad,H.E.; Gad, H.E. Development of a new temperature data acquisition system for solar energy applications. Renew. Energy 2015, 74, 337-343. [CrossRef]

49. Iskandar, H.R.; Purwadi, A.; Rizqiawan, A.; Heryana, N. Prototype development of a low cost data logger and monitoring system for PV application. In Proceedings of the 3rd IEEE Conference on Power Engineering and Renewable Energy, ICPERE, Shah Alam, Selangor, 21-22 November 2016; Institute of Electrical and Electronics Engineers Inc.: Piscataway, NJ, USA, 2017; pp. 171-177.

50. JCGM/WG 1 Evaluation of measurement data-Guide to the expression of uncertainty in measurement. GUM 2008, 50, 134.

(C) 2020 by the authors. Licensee MDPI, Basel, Switzerland. This article is an open access article distributed under the terms and conditions of the Creative Commons Attribution (CC BY) license (http://creativecommons.org/licenses/by/4.0/). 